NBSIR 78-1415

\title{
Fire Endurance Tests of Residential Walls Containing Branch Circuit Wiring - Preliminary Findings
}

Lionel A. Issen

Center for Fire Research

Institute for Applied Technology

National Bureau of Standards

Washington, D.C. 20234

February 1978

Final Report

Sponsored in party by:

Office of Policy Development and Research

U.S. Department of Housing and Urban Development

Washington, D.C. 20410 



\section{FIRE ENDURANCE TESTS OF}

RESIDENTIAL WALLS CONTAINING

BRANCH CIRCUIT WIRING -

PRELIMINARY FINDINGS

Lionel A. Issen

Center for Fire Research

Institute for Applied Technology

National Bureau of Standards

Washington, D.C. 20234

February 1978

Final Report

Sponsored in part by:

Office of Policy Development and Research

U.S. Department of Housing and Urban Development

Washington, D.C. 20410

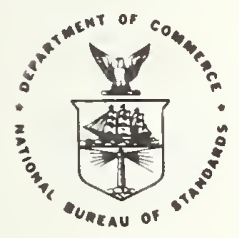

U.S. DEPARTMENT OF COMMERCE, Juanita M. Kreps, Secretary

Dr. Sidney Harman, Under Secretary

Jordan J. Baruch, Assistant Secretary for Science and Technology

NATIONAL BUREAU OF STANDARDS, Ernest Ambler, Director 

LIST OF FIGURES . . . . . . . . . . . . . . . . . . . . . . . . . . . . iv

Abstract . . . . . . . . . . . . . . . . . . . . . . . . . . 1

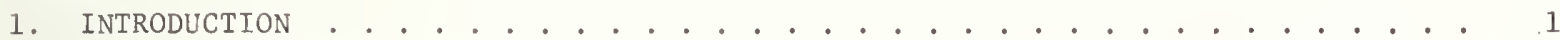

2. TEST ARRANGEMENT . . . . . . . . . . . . . . . . . . . . . . . . . . 3

2.1. Construction Details, Wall No. 1 . . . . . . . . . . . . . . . . 3

2.2. Construction Details, Wall No. 2 . . . . . . . . . . . . . . . . . . 4

3. INSTRUMENTATION . . . . . . . . . . . . . . . . . . . . . . . . . 4

3.1. Wall No. 1 . . . . . . . . . . . . . . . . . . . . 4

3.2. Wall No. 2 . . . . . . . . . . . . . . . . . . . . 5

4. TEST RESULTS . . . . . . . . . . . . . . . . . . . . . . . . 5

4.1. Wall No. 1 General Test Notes... . . . . . . . . . . . . . . . 5

4.1.1. Insulated Wall . . . . . . . . . . . . . . . . . 6

4.1.2. Uninsulated Wall . . . . . . . . . . . . . . . . . 6

4.2. Wall No. 2 General Test Notes . . . . . . . . . . . . . . . . . 7

4.2.1. Insulated Wall . . . . . . . . . . . . . . . . 7

4.2.2. Uninsulated Wall . . . . . . . . . . . . . . . . . 7

5. DISCUSSION OF RESULTS . . . . . . . . . . . . . . . . . . . . . . . . . . . 8

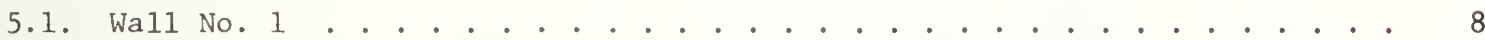

5.2. Wall No. 2 . . . . . . . . . . . . . . . . . . . . . 9

5.3. Both Walls . . . . . . . . . . . . . . . . . . . . . 9

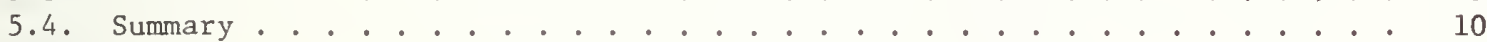

6. REFERENCES . . . . . . . . . . . . . . . . . . . . . . . . . 11

APPENDIX A - TEST OBSERVATIONS . . . . . . . . . . . . . . . . . . . . . . 12

A.1. Summary of Observations - Test FE 1 . . . . . . . . . . . . . . . . 13

A.2. Summary of Observations - Test FE 2 . . . . . . . . . . . . . . . 15 
Figure 1. Test FE 1 - Construction and instrumentation . . . . . . . . . 18

Figure 2. Wall No. 1, steel electric boxes... . . . . . . . . . . . . 19

Figure 3. Wall No. 1 prior to inserting Insulation . . . . . . . . . . . 20

Figure 4. Electric boxes . . . . . . . . . . . . . . . . . 21

Figure 5. Test FE 2 - Construction and Instrumentation . . . . . . . . . 22

Figure 6. Wall 2 prior to applying second face.............. . 23

Figure 7. Wall 1 immediately prior to test. Note clocks on left. . . . . . 23

Figure 8. Wiring diagram for electric clocks . . . . . . . . . . . . . 24

Figure 9. Test FE 2 - Front view wall in place. Note t/c lead to receptacles and to switch plates. ............... . . 25

Figure 10. Test FE 2 - Clock setup . . . . . . . . . . . . . . 26

Figure 11. Test FE 1 - Furnace pressure . . . . . . . . . . . . . . . 27

Figure 12. Test FE 1 - Insulated wall NM switch box temperatures . . . . . . 28

Figure 13. Test FE 1 - Uninsulated wall switch box temperatures . . . . . . . . 29

Figure 14. Test FE 1 - Insulated wall AC switch box temperatures . . . . . . . 30

Figure 15. Test FE 1 - Uninsulated wall AC switch box temperatures . . . . . . . 31

Figure 16. Test FE 1 - Insulated wall MM fire side temperatures . . . . . . . . 32

Figure 17. Test FE 1 - Insulated wall NM room side temperatures . . . . . . . 33

Figure 18. Test FE 1 - Insulated wall AC fire side temperatures . . . . . . . . 34

Figure 19. Test FE 1 - Insulated wall AC room side temperatures . . . . . . . 35

Figure 20. Test FE 1 - Air temperatures insulated wall . . . . . . . . . 36

Figure 21. Test FE 1 - Uninsulated wall MM fire side temperatures . . . . . . . 37

Figure 22. Test FE 1 - Uninsulated wall NM room side temperatures . . . . . . 38

Figure 23. Test FE 1 - Uninsulated wall AC fire side temperatures . . . . . . . 39

Figure 24. Test FE 1 - Uninsulated wall AC room side temperatures . . . . . . . 40

Figure 25. Test FE 1 - Uninsulated wall air space temperatures . . . . . . . 41

Figure 26. Test FE 1 - Furnace temperatures . . . . . . . . . . . . . . . 42

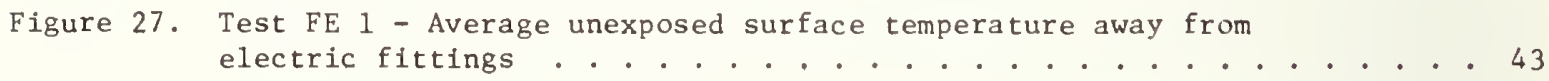

Figure 28. Test FE 2 - Furnace pressure . . . . . . . . . . . . . . . . 44

Figure 29. Test FE 2 - Air temperatures lower insulated wall . . . . . . . . 45

Figure 30. Test FE 2 - Air temperatures floor space insulated wall . . . . . 4 46

Figure 31. Test FE 2 - Air temperatures upper insulated wall . . . . . . . . 47

Figure 32. Test FE 2 - Air temperatures lower uninsulated wall . . . . . . . 48

Figure 33. Test FE 2 - Air temperatures floor space uninsulated wall . . . . . 49

Figure 34. Test FE 2 - Air temperatures upper uninsulated wal1 . . . . . . . 50

Figure 35. Test FE 2 - NM Insulated upper wall room side temperatures . . . . . . 51

Figure 36. Test FE 2 - AC insulated upper wall room side temperatures . . . . . . 52

Figure 37. Test FE 2 - MM uninsulated upper wall room side temperatures . . . . . 53

Figure 38. Test FE 2 - AC uninsulated upper wall room side temperatures . . . . 54 
Figure 39. Test FE 2 - Furnace temperatures . . . . . . . . . . . . . . . 55

Figure 40. Test FE 2 - Average unexposed surface temperatures . . . . . . . . . 56

Figure 41. Test FE 2 - Mounted TV camera . . . . . . . . . . . . . . . . . 57

Figure 42. Test FE 1 - Smoke coming out of AC (2) insulated and NM uninsulated

(3) switches . . . . . . . . . . . . . . . . 58

Figure 43. Test FE 1 - Front of furnace at end of test . . . . . . . . . . . 58

Figure 44. Test FE 1 - Front of furnace 3 hours after end of test . . . . . . . 59

Figure 45. Test FE 2 - Burn-through at end of test . . . . . . . . . . . . . . 60

Figure 46. Test FE 2 - Condition of wall 2 hours after end of test...... . . 60 

FIRE ENDURANCE TESTS OF RESIDENTIAL WALLS

CONTAINING BRANCH CIRCUIT WIRING - PRELIMINARY FINDINGS

Lionel A. Issen

Abstract

Two fire endurance tests were performed to study the effects of branch circuit electric wiring and wiring devices on the fire resistance of a gypsum board and wood stud one-hour fire-rated wall. The tests simulated potential fire spread between (a) horizontally adjacent occupancies and (b) vertically adjacent occupancies. Each test wall assembly included both nonmetallic sheathed cable (type NM) and armoured cable (type AC), with and without 3-1/2 inch thick glass fiber insulation. The tests were conducted with a slightly positive pressure in the furnace, to represent the overpressure generated in room fires.

The tests showed that the presence and penetrations of electric branch circuit cables and wiring devices lowered the fire resistance of a onehour rated gypsum board and wood-stud wall by 13 minutes when based on flame penetration of the unexposed surface wallboard and by 23 minutes when based on flame penetration at the wiring devices. The tests showed no significant difference in the performance of the different cable types.

Key words: Fire endurance; fire tests; PVC; smoke; walls; wiring; branch circuits; electrical codes.

\section{INTRODUCTION}

Beginning with the 1975 edition, the National Electric Code [1] ${ }^{1}$ restricts the use of nonmetallic sheathed cable to buildings of three stories or less above grade. Many local codes further restrict the use of nonmetallic sheathed cable in their jurisdictions. In order to provide information that would clarify the need for these restrictions, the Department of Housing and Urban Development (HUD) requested that the National Bureau of Standards develop data on the effect of electric branch circuits and wiring devices on the fire endurance of residential wall construction.

$\overline{1_{\text {Numbers in brackets }}}$ refer to references 1 isted at the end of this paper. 
The two tests reported here address questions concerning the contribution of branch circuit wiring and their penetration through fire barriers to the spread of fire and smoke, assuming a fire of any cause started in one dwelling of a multi-family residential building, such as an apartment building. The standard method of rating wall assemblies and floor assemblies for their ability to serve as a fire barrier between adjacent occupancies is the ASTM E-119 fire endurance test [2] which is considered to represent the complete burnout of combustibles within the occupancy. However, this test is often conducted on an assembly in which the electrical wiring, outlet boxes, switches, and other penetrations are not included, and with no stated criteria for possible smoke generation or penetration through the wall or floor assembly. In addition, little or no consideration is given to the pressure differences likely to be experienced across the assembly, even though this may have an appreciable effect on fire and smoke movement.

Such questions need to be considered if one is to make a technically valid judgment on the fire contribution of branch circuit cables of different types, such as nonmetallic sheathed cable (type NM), armoured cable (type AC), electrical metallic tubing (EMT), flexible metal conduit, and rigid metal condult.

The test for electric wiring used by Underwriters' Laboratories [3,4] is a type of ease of ignition test. It cannot be used for evaluating the effect of the electrical wires on the fire resistance of a fire barrier. To the best of our knowledge, no controlled laboratory tests have been conducted to measure the relative effect of different kinds of electric cables on the fire endurance of residential wall construction; these reported tests represent an inftial step in developing such information.

In this preliminary investigation the following factors were included in the test: (a) one generic wall type, (b) two insulation levels (3-1/2 inch glass fiber, no insulation), (c) two cable types (NM and $\mathrm{AC}$ ), and (d) two paths for fire transmission (horizontal and vertical). Other factors such as multiple cables, additional types of cable (EMT, metal conduit, plastic conduit), aged insulation, nonmetallic boxes, and smoke measurements may be examined in future tests.

The purposes of the work described in this report were to (1) determine the effect on the fire endurance of a one-hour fire-rated wall due to the installation of branch circuit wiring using either NM or AC cable and (2) to examine the potential for fire spread through the wa11 to the floor above due to the installation of branch circuit wiring. 
After consultation with the sponsor and the industry sources, a generic one-hour rated wood stud wa11, WP3341, was chosen from the "Fire Resistance Design Manual" [5], page 36. Since a fire-rated wall used between separate occupancies may or may not contain insulation for sound and thermal needs, each wall was divided into two parts, insulated and uninsulated. The test of the first wall assembly simulated a fire between horfzontally adjacent occupancies. The test of the second wall simulated a fire between vertically adjacent occupancies: a situation in which fire could spread vertically within and through a partition from a room on one level to another occupancy on the level above.

\subsection{Construction Details, Wal1 No. 1}

The wall used in the first test was constructed of $2 \times 4$ inch (nominal) wood studs with a composite layer of one 1/2-inch type X gypsum board and one 1/4-inch gypsum wall board on each face. This wall, which is shown in figure 1, was divided by a thermal barrier into two equal elements. The thermal barrier consisted of two studs separated by 5/8-inch thick type X gypsum board. The west (left) half was insulated with $3-1 / 2$ inches thick paper faced glass fiber; the east (right) half was uninsulated. The two parts of the assembly were otherwise identical in construction and instrumentation.

Each element contained three full 16-inch stud spaces plus a partial space at the end that were not instrumented. The first full stud space contained nonmetallic sheathed cable (type NM); the second contained no cables and was used as a reference; the third contained metal sheathed cable (type AC).

The first and third stud spaces contained the following electrical equipment: two switches, two double receptacle boxes, and four cables (one to each of the electric terminals). One switch and one box in each stud space faced the furnace; the others faced the room. The electrical boxes were metal. A photograph of a typical stud space prior to closing in the wall is shown in figure 2. The construction of wall 1 just prior to applying the insulation 1s shown in figure 3. In this assembly the cables penetrated the wall at the top. The armoured cables contained two No. 12 (AWG) copper wires, and the type NM cable contained three No. 12 copper wires including a ground wire. The cables conformed to the requirements of the National Electric Code [1]. The boxes were stamped with the UL logo indicating that they met the appropriate UL standards [6]. The switch and outlet boxes were 3 inches high $x$ 2 inches wide $\times$ 2-1/2 inches deep; the metal was 1/16-1nch thick. A photograph of one of the electric boxes is shown in figure 4. 
The wall used in the second test is shown in figure 5. The basic construction is the same as that of the first wall. The lower half of the test wall represented the upper half of the wall of one residence, while the upper half of the test wall represented the lower half of the wall of the adjacent residence one story above, with a floor space between them. In the lower half of the test wall switches and outlet boxes faced the furnace, while in the upper half they faced the test room. To reduce the amount of heat entering the upper half of the wall from the furnace, it was protected by an extra layer of $5 / 8$ inch type $\mathrm{X}$ gypsum board which extended from the top of the assembly down to the level of the headers on the lower wall.

As in the first test, the insulated and uninsulated halves of the wall were separated by a thermal barrier. The west end of the wall was insulated with $3-1 / 2$ inch thick aluminum backed glass fiber insulation, while the east half was uninsulated. At the time of this test, paper backed insulation was not readily available, and so aluminum backed insulation was used. This is believed to have had only a negligible effect on this test.

As in the first wall test each half contained three full 16-inch stud spaces plus a partial stud space at the end. The first full stud space contained nonmetallic sheathed cable (type NM); the second contained no cable and was used as a reference; and the third contained metal sheathed cable (type AC). In this assembly the electric cables were introduced through the bottom plate. The holes that allowed the cables to pass from the lower to the upper level were 7/8-inch diameter. Figure 6 shows the construction of the wall prior to applying the second face.

\section{INSTRUMENTATION}

\subsection{Wa11 No. 1}

Each stud space containing electric wiring had one thermocouple ( $t / c$ ) on each of the four electric boxes, one $t / c$ on each of the four electric cables, one t/c measuring the stud space temperature, one $t / c$ under the switch plate (on the room side), and one t/c in the prong space for a total of $11 \mathrm{t} / \mathrm{cs}$. Each empty stud space contained a single t/c that monitored the stud space temperature and was used as a reference for the other two stud spaces. For convenience the stud space temperatures are referred to as the air temperatures. Twelve ASTM surface $t / c s$ on the exposed surface completed the $t / c$ instrumentation of the specimen, see figure 1. During the test both the furnace temperatures and furnace pressures were monitored. Sixteen clocks were connected, one to each switch and one to each outlet box, and were used to determine when a circuit became inoperative. The circuits were arranged to disconnect the clocks when either a ground short or wire break occurred. A photo of the clocks is shown in figure 7 and a wiring diagram in figure 8. 


\subsection{Wa11 No. 2}

Each stud space that contained electric fittings had a $t / c$ on each electric box, one $t / c$ on the cable and one $t / c$ measuring the alr temperature. The floor space between the upper and lower walls had $a t / c$ on the cable and $a t / c$ measuring the air temperature. In the insulated wall each measurement of the air temperature is derived from two t/cs arranged In parallel, to give an average of the alr temperatures on both sides of the insulation. Each of the spaces used as a reference contalned a t/c to monitor the air temperature.

In addition to the t/cs within the wall, a t/c was placed inside a prong space of each electrical plug and at each switch under the switch plate on the room side. These t/cs monitored the temperatures at these wiring devices. As with wall No. 1 , there were 12 ASTM surface $t / c s$ on the unexposed surface. These $t / c s$ are shown in figure 9.

Eight clocks shown in figure 10 were connected, one to each of the room side and fire side cables. The electric circuit was set to stop the clocks if either a ground short or wire break occurred during the test.

\section{TEST RESULTS}

\subsection{Wall No. 1 General Test Notes}

A malfunction of the furnace exhaust damper control system during the first 16 minutes of the first test resulted in high furnace pressures. At 16 minutes the automatic damper controls were disconnected and the furnace pressure was controlled manually for the balance of the test at approximately +0.1 inch water column. This value is representative of the overpressure in a room during a severe fire. The measured furnace pressure history is shown in figure 11 .

High furnace pressures produce a more severe fire exposure on a wall than do low or negative pressures. This is shown in test FE 1 by comparing the temperatures of the switch boxes on the fire side with those on the room side (figures 12-15). The fire side temperatures showed a steady rise for the first 16 minutes of test time, followed by a decreasing temperature for about 8-10 minutes. These temperatures remained higher until about 25-30 minutes into the test when both the fire side and room side temperatures rose sharply. This sharp rise in temperature coincided with the observation that the fire side gypsum board was deteriorating. 


\subsubsection{Insulated Wall}

With minor exceptions, the temperatures on both the fire side and the room side of the insulated half of the wall showed no significant difference between the type NM and type AC assemblies. The temperatures are shown in figures 16, 17, 18, and 19.

The air space temperatures shown in figure 20 for three insulated stud spaces showed that there was no significant difference between the air space temperatures for the type NM and AC assemblies. The NM air space appears to have been influenced by the high furnace pressures for several minutes prior to the damper control change at 16 minutes. This $t / c$ may have been inadvertently located toward the fire. With this qualification, the air temperatures remained relatively low until the wall deteriorated exposing the stud spaces to the direct furnace heat after about 25 minutes.

\subsubsection{Uninsulated Wall}

The temperatures on both the fire side and room side of the uninsulated half of the wall showed no significant differences between the type NM and the type AC assemblies. The temperatures are shown in figures $21,22,23$, and 24 .

The alr space temperatures, shown in figure 25, also showed no significant differences between the three stud spaces.

At fallure a difference was observed in the temperatures of the electric elements (boxes and cables). When the fire side wall facing falled, the temperature of the electric elements in the insulated NM stud space rose more closely together than in the uninsulated NM stud space. This can be seen by comparing figures 16 and 21 , and 17 and 22 . In the $\mathrm{AC}$ stud spaces the opposite occurred, that is, the temperatures in the uninsulated stud space rose more closely together than those in the insulated stud space. This can be seen by comparing figures 18 and 23, and 19 and 24 . Based on the performance of a single test it is not possible to determine whether these differences were due to normal test variations or to difference in performance of the two cable types.

The furnace temperatures, which were controlled to follow the standard ASTM E-119 curve [2], are shown in figure 26. The correction to the fire endurance based on the method given in ASTM E-119 was +0.7 minute. The average unexposed surface temperature measured by $t / c s 39$ to 50, away from the switch and outlet boxes, is shown in figure 27. 
Prior to this test, the furnace damper control was changed to allow for better control of the furnace pressure than occurred during the first test. The furnace pressures, shown in figure 28, were under better control than in the first test except for the initial 2-1/2 minutes when furnace pressures were unstable. After 10 minutes of test time the average furnace pressure was +0.09 inch water column.

Because this wall simulated a two-story assembly, each half (insulated and uninsulated) had three elements. These elements are the lower wall, the floor space, and the upper wall.

For both the insulated and uninsulated halves of the wall, the temperatures marked "outlet air" (t/cs 59, 60, 61, and 62 on figures 35, 36, 37, and 38 respectively) were erratic and should be ignored.

\subsubsection{Insulated Wa11}

In this wall the air temperature in each element was measured by a pair of $t / c s$ connected in parallel. One $t / c$ was on the fire side of the insulation, the other on the room side. Thus the air temperatures are the average of these on the room side and fire side.

The lower wall temperatures rose more or less uniformly for the first 40 minutes of the test, while the upper wall and floor space temperatures remained low until this time, when the wall deteriorated rapidly (see figs. 29-31). This was to be expected as the upper wall and floor space were protected from direct furnace heat by an extra layer of gypsum board and had no electric boxes or other penetrations facing the furnace.

\subsubsection{Uninsulated Wall}

In a general way the air temperatures which are shown in figures 32,33 , and 34 in the uninsulated wall were similar to those in the insulated wall, except that the fire side appeared to fail after about 52 minutes of test. The temperatures in the AC space rose only moderately. This may be due in part to local conditions in the furnace during the test and to the manner in which the wall failed.

The outlet box temperatures, outlet box air temperatures and neighborhood ASTM surface temperatures on the room side of the upper wall are shown in figures $35,36,37$ and $38 . \quad$ In general, the temperatures of the floor space and upper space air and cables were related to the deterioration of the wall during the test. 
The average furnace temperature which was constrained to follow the standard ASTM E-119 [2] time-temperature curve is shown in figure 39. The correction to the fire endurance based on the method given in ASTM E-119 was + 0.9 minutes.

The average surface temperatures (t/cs 63 to 74) away from the electric boxes are shown in figure 40 .

In this test, a TV camera was installed to make a video tape of the exposed wall surface during the test. However, because of the high thermal flux radiated through the observation window it was necessary to remove the camera at 24 minutes. A simple compact technique of protecting the TV camera from the furnace heat needs to be developed before 1 t can be used effectively to monitor the furnace conditions during a fire test. A picture of the mounted TV camera is shown in figure 41.

\section{DISCUSSION OF RESULTS}

5.1. Wa11 No. 1

The configuration in the first test was intended to simulate a severe fire condition in one dwelling unit sharing a common wall with a horizontally adjacent occupancy. During the planning for the first test, it was noted that although paragraph 405-7.12 of the Minimum Property Standards (MPS) [7] prohibits back-to-back electric boxes, it does not prohibit opposite facing electric boxes in the same stud space. Since this appears to represent a severe condition, and possibly an oversight in the MPS, it was included in the first test.

The exposure severity was increased due to the high positive furnace pressure during the first 16 minutes of test. Notwithstanding these factors, the rise of temperatures within the wall stud spaces, which can be taken as a measure of fire penetration within the wall, appears closely related to the failure of the fire side gypsum board layer. This failure was indicated by an abrupt rise in the recorded temperatures in the stud spaces and by visual observation. In the insulated half of the wall the air temperatures rose abruptly at an average time of 26 minutes, while in the uninsulated half of the wall they rose abruptly at an average time of 28 minutes. The observations (see appendix) indicate that the outer layer of gypsum board was deteriorating at 22 minutes. The differences in the NMwired and AC-wired assemblies were slight as measured by the times at which the air temperatures in the stud spaces rose abruptly. This is in part due to the high furnace pressures and the placement of opposite facing electric boxes within the stud space which allowed hot furnace gases to enter the stud space. This probably masked the effect of the insulation in the insulated half of the wall. 


\subsection{Wall No. 2}

The results of the first test were in a general way confirmed by the second test. This test configuration was intended to simulate representative conditions in which a severe fire exists in the lower dwelling unit of vertically adjacent occupancies. The insulated wall fire side deteriorated after 40 minutes, while the uninsulated wall fire side deteriorated after about 50 minutes. The differences may be due to the insulation acting as a thermal barrier to heat loss and causing the fire side of the insulated wall to heat up faster than the uninsulated wall. In the first test this effect was largely masked by the differences in construction and by the higher furnace pressures.

The differences between the AC and NM assemblies are probably not significant. For example, for the insulated type NM and type AC upper electric box temperatures, the temperatures in the NM assembly rose 3 to 5 minutes earlier than in the type AC assembly; in the uninsulated wall, the type NM temperatures also rose later than the type AC temperatures but by only a few minutes. This may have been due to local differences in the furnace and the way the fire side of the wall failed rather than due to basic differences in the type of wiring in the two assemblies.

It should be noted that the temperature rise in the upper air spaces is related to the failure times of the gypsum board on the fire side.

\subsection{Both Walls}

The presence of insulation in the west half of each of the two wall test units reduced the time at which the west side fire side gypsum board fell off. The criterion indicating a break-in of fire into the stud space was taken to be an abrupt rise in the average stud space alr temperature. For test FE 1, the average air space temperature rose abruptly at 26 and 28 minutes, respectivelv, in the insulated and uninsulated halves of the wall. In test FE 2, the average air space temperature in the lower wall spaces rose abruptly at about 42 and 52 minutes in the insulated and uninsulated halves of the wall, respectively. In test FE 1, the effect of the insulation on the performance of the wall was partially misked both by the presence of opposite facing electric fixtures in the same stud space and by the high furnace pressures during the first 16 minutes of test.

In the first test a burn-through occurred at switch No. 4 (AC uninsulated) at 37 minutes (see "Observations" in appendix), while in the second test in which opposite facing electric boxes were separated by structural elements the assembly maintained its fire resistance for 57 minutes (see "Observations" in appendix). This suggests that blocking of the penetrations would be helpful in maintaining the fire resistance of a fire barrier for the 
desired time period. Previous work at NBS on other projects [8-10] have shown that blocking the spaces around penetrations and using thermal barriers may be effective in maintaining the fire resistance of rated assemblies for the desired period.

The differences in the fire performance between type $M M$ and type AC branch circuit cables, within a particular one-hour fire rated wall assembly, as shown by these tests is slight. More tests are required to determine any differences between these and other cable types such as EMT, plastic, and metal conduit. Additional factors that need to be examined are smoke and toxic gas emission by the insulation and the flow of hot gases along the paths provided by the cables or conduit.

These conclusions apply only to a single cable or at most two single cables penetrating a stud space under the conditions of test. They may not apply to bundles of cables or to many cables passing through a stud space. Also, no conclusions can be made on the integrity of other types of wall construction under fire exposure, particularly those which may be more sensitive to differences in furnace pressure.

\subsection{Summary}

The tests showed that the presence and penetrations of electric branch circuit cables and wiring devices lowered the fire resistance of a one-hour rated gypsum board and wood stud wall to 47 minutes when based on flame penetration of the unexposed surface wallboard and to 37 minutes when based on flame penetration at the wiring devices. The tests showed little effect of the cable types on the fire performance of the walls. The reduced fire resistance appears to be more related to the cut-outs for the electric boxes than to the presence of electric cables. 


\section{REFERENCES}

[1] National Electric Code, NFPA 70-75, National Fire Protection Association, Boston, Massachusetts (1975).

[2] Standard Methods of Fire Tests of Building Constructions and Materials, ASTM Designation E-119-73, American Society for Testing and Materials, Philadelphia, Pennsylvania (1975).

[3] Standard for Rubber - Insulated Wires and Cables, UL 44, Underwriters' Laboratories, Northbrook, Illinois (1975) and Amendments dated June 8, 1976. A1so listed as ANSI C33. 6-1974.

[4] Standard for Thermo-P1astic Insulated Wires, UL 83, Underwriters' Laboratories, Northbrook, Illinois (1971). Also listed as ANSI C33. 80-1971.

[5] Fire Resistance Design Manual 1975-76 Edition, Gypsum Association, Evanston, Illinois (1975).

[6] Standard for Outlet Boxes and Fittings, UL 514, Underwriters' Laboratories, Northbrook, Illinois (Revised June 18, 1976). Also listed as ANSI C 33. 84-1973.

[7] Minimum Property Standards for Multi-family Housing, Including Revisions 1, 2, and 3, Report 4910.1, Department of Housing and Urban Development, Washington, D.C. (1973).

[8] O'Neill, J. G. and Breese, J. N., Report of Test on Steel Truss Floor-Ceiling Assembly, Nat. Bur. Stand. (U.S.) (1973), unpublished report.

[9] Issen, L. A., Development of a Fire Test Method for Flexible Connections in Air Distribution Systems, NBSIR 75-673, Nat. Bur. Stand. (U.S.) (1975).

[10] Parker, W. J., Paabo, J. T., Benjamin, I. A. and Gross, D., Fire Endurance of Gypsum Board Walls and Chases Containing Plastic and Metallic Drain, Waste and Vent Plumbing Systems, BSS 72, Nat. Bur. Stand. (U.S.) (September 1975). 
APPENDIX A

TEST OBSERVATIONS 
hr:min:s

$00: 00$

00:01

$00: 04$

$00: 05: 30$

$00: 07$

$00: 09$

$00: 11$

$00: 19$

$00: 22$
Start test

Smoke is coming out of all switches and receptacles. The smoke is irritating to observers standing near the test wall.

Except for Switch 非, on the room side, smoke is coming out of al1 the switches and outlets. Smoke is also coming out of top of the assembly where the electric cables penetrate the gypsum board.

The smoke has a distinct acrid smell. Smoke is mostly a whitish color. ASTM surface temperatures still low $\left(25^{\circ} \mathrm{C}\right)$.

Switch 非 1 on unexposed side and space 1 (NM insulated) still has the least amount of smoke coming out of it.

The smoke from the switches and receptacles projects about 1 foot in front of the wall before turning vertical. On the fire side the switch clocks are still operating.

Most smoke and gases seem to be coming out of stud space 4 (NM uninsulated wall). The smoke and gases from stud space 6 (AC uninsulated) is only a little less than from 4 space (NM uninsulated). See figure 42.

Smoke and fumes are strong at the top of the furnace.

Switch 非 (stud space 1 MM insulated) is now generating as much smoke as the other switches.

A plece of gypsum board on the insulated half of the wall near the middle fell into the furnace.

The switch and receptacle plates on the unexposed side are melting. 
$00: 30$

The exposed gypsum board appears to have completely fallen into the furnace. On the room side, smoke is coming out of the top and sides down to the mid-height of the assembly. Some smoke is also coming out of the bottom of the assembly.

$00: 34$

The whole furnace area is full of choking smoke that stings the eyes; at the top of the furnace conditions are untenable.

$00: 37$ Burn-through in switch 非 (stud space 6, AC uninsulated).

$00: 38$ Burn-through in outlet 非 (stud space 1, NM insulated).

$00: 39: 30$ Jet of flame coming out of switch 非 (stud space 1, MM insulated).

$00: 42$ Burn-through switch 非 (stud space 3, AC insulated)

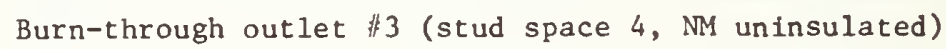
Burn-through switch 非 (stud space 4, MM uninsulated)

$00: 45$ Flame-through at 非 3 switch (stud space 4, NM uninsulated) Flame-through at 非 4 outlet, and $\left.\right|^{4}$ switch (stud space 6 , AC uninsulated) End of test. See figure 43.

$00: 48$ Complete fire break-through at stud spaces 4 and 5 . No structure behind the gypsum board.

\section{Post Fire Conditions}

It should be noted that after the end of the test the wall continued to burn. After the debris had cooled they were examined. They showed that the insulation had pyrolyzed, and the wires had partly melted confirming the $t / c$ data that some of the cables' temperatures had exceeded the melting point of copper $\left(1082^{\circ} \mathrm{C}\right)$. An examination of the cable temperature records shows that in the insulated stud spaces the cable temperatures exceeded $1082^{\circ} \mathrm{C}$ at 40 minutes for the $N M$ (see figure 16). In the uninsulated stud space temperatures of both the NM and the AC cable remained below $1082^{\circ} \mathrm{C}$.

The condition of the wall about three hours after the test is shown in figure 44. 
hr:min:s

$00: 00$

$00: 08$

$00: 10$

$00: 11: 30$

$00: 14$

$00: 16$

$00: 17$

$00: 18$

$00: 24$

\section{Start test}

Some steam coming out of the side edges of the wall about $1-1 / 2 \mathrm{ft}$ above the bottom.

At top of the furnace there is very little irritating gases and smoke.

More vapor coming out of the lower side edges of the wall. Some smoke or vapor running out of stud space \#3 (uninsulated NM).

More smoke coming out of stud spaces $\|_{1} 1, \# 3$, and $\mid ⿰ 4$ and at the vertical edges of the wall down to about 2 feet above the bottom. Stud space 非 3 has the most smoke coming out.

Considerable smoke coming out of the lower left (west) vertical edge (insulated side).

On fire side, upper part of wall appears to be in good shape. Portions of the joint between the insulated and uninsulated wall are glowing bright yellow.

Smoke is coming out of all the stud spaces. The most smoke is coming out of stud spaces $\|_{4}$ and 非 (uninsulated wall). Stud spaces \#1 and $\|_{3}$ (insulated wall) are emitting less smoke than stud spaces \#4 and 非6. Stud space 非 1 is emitting the least smoke, stud space \#4 is emitting the most. On the fire side the center joint has opened about $1 / 2$ inch.

Hot smoke and gases are coming out of the wall and are impinging on the TV camera. (The camera was removed to avoid permanent damage to $i t$ ). 
$00: 26$

$00: 27$

$00: 31$

$00: 32$

$00: 33$

$00: 34$

$00: 35$

$00: 39$

$00: 45$

$00: 47$

$00: 48$

$00: 57$

$00: 59$

Smoke continues to be emitted from those stud spaces with cables in them. More smoke appears to be coming out of the uninsulated wall than out of the insulated wall. On the fire side the joint between the wall sections has opened 1 inch.

The smoke at the top of the furnace smells mostly like wood smoke.

Flaming at vertical joint on fire side.

Much smoke coming out of the stud space 非 through the receptable and switch.

Smoke is coming out of the bottom of the wall. The smoke is coming mostly from the stud spaces where there is electric wiring.

On the insulated wall on the fire side the upper layer of gypsum board (added for extra heat resistance) has started to peel off from the lower middle to the upper diagonal corner, exposing the upper wall to the direct furnace heat.

About half of the extra gypsum board is peeling off and falling into the furnace and the upper wall is beginning to deteriorate.

The cover plates on the switches and receptacles are melting. The gypsum board in the vicinity of the plates is stained by melting plastic.

On the lower middle fire side the gypsum board has come off exposing the studs to the direct heat of the furnace.

On the fire side the middle joint has opened up about 2 inches.

A hole, $3 \mathrm{ft}$ diameter, has opened on the fire side at the middle joint near the bottom, exposing the studs to direct furnace heat.

There is a burnt spot on the front of the wall. It is about 1-1/2 feet above the bottom and 6 inches from the left edge (west).

Burn-through at a point about 1-1/2 feet above the bottom and 6 inches from the left edge (west). 
Burn-through at the middle of the wall just after the test was ended, see figure 45.

\section{Post Fire Conditions}

A photo of the debris after the end of the test is shown in figure 46 . The melting of the wires appeared to be similar to that in the first test, thus confirming the $\mathrm{t} / \mathrm{c}$ data that the cables' temperatures had exceeded the melting point of copper $\left(1082^{\circ} \mathrm{C}\right)$. The recorded data and figures 32 to 37 indicate that these temperatures were approached when the fire side face of the wall was allowed to burn after the furnace was turned off. 


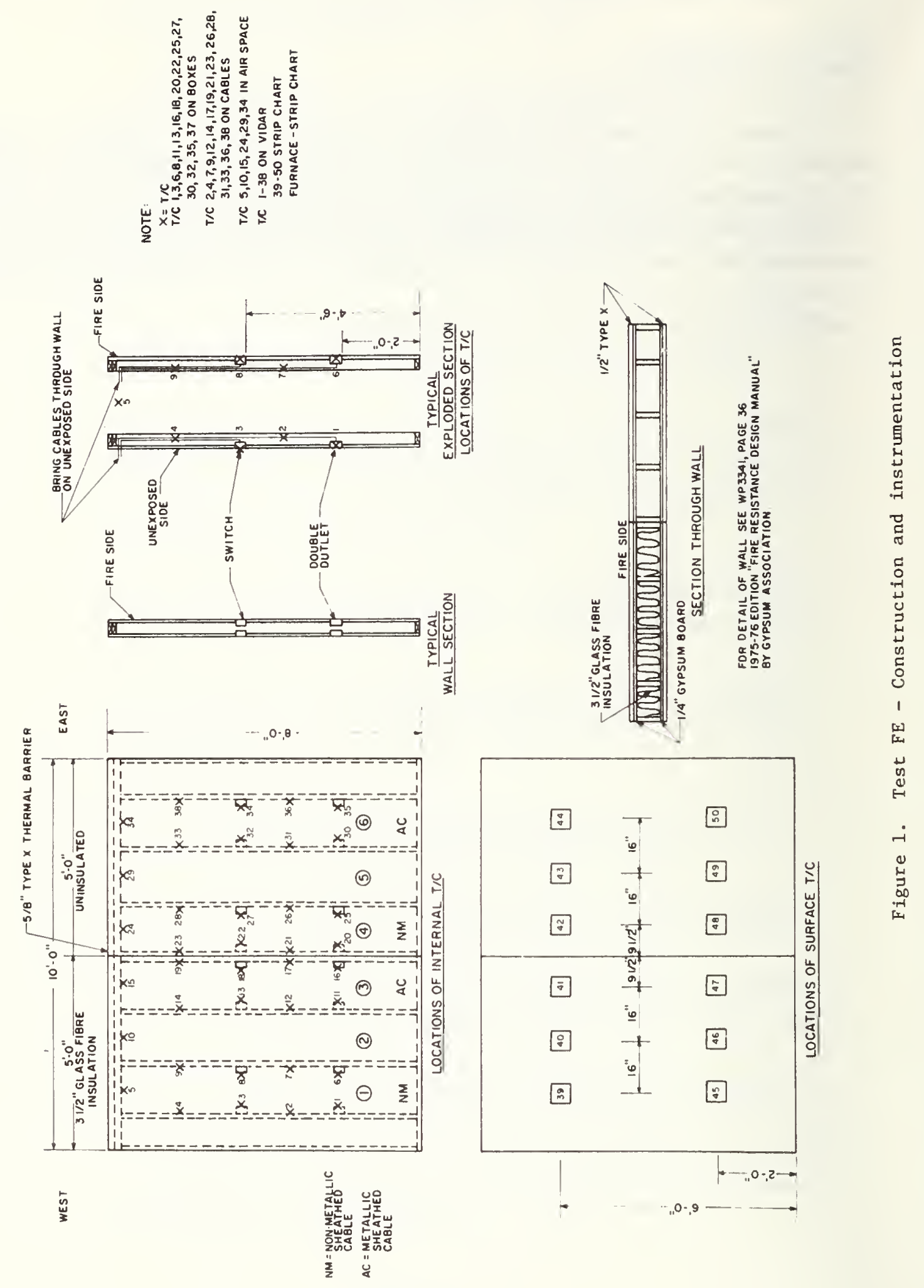




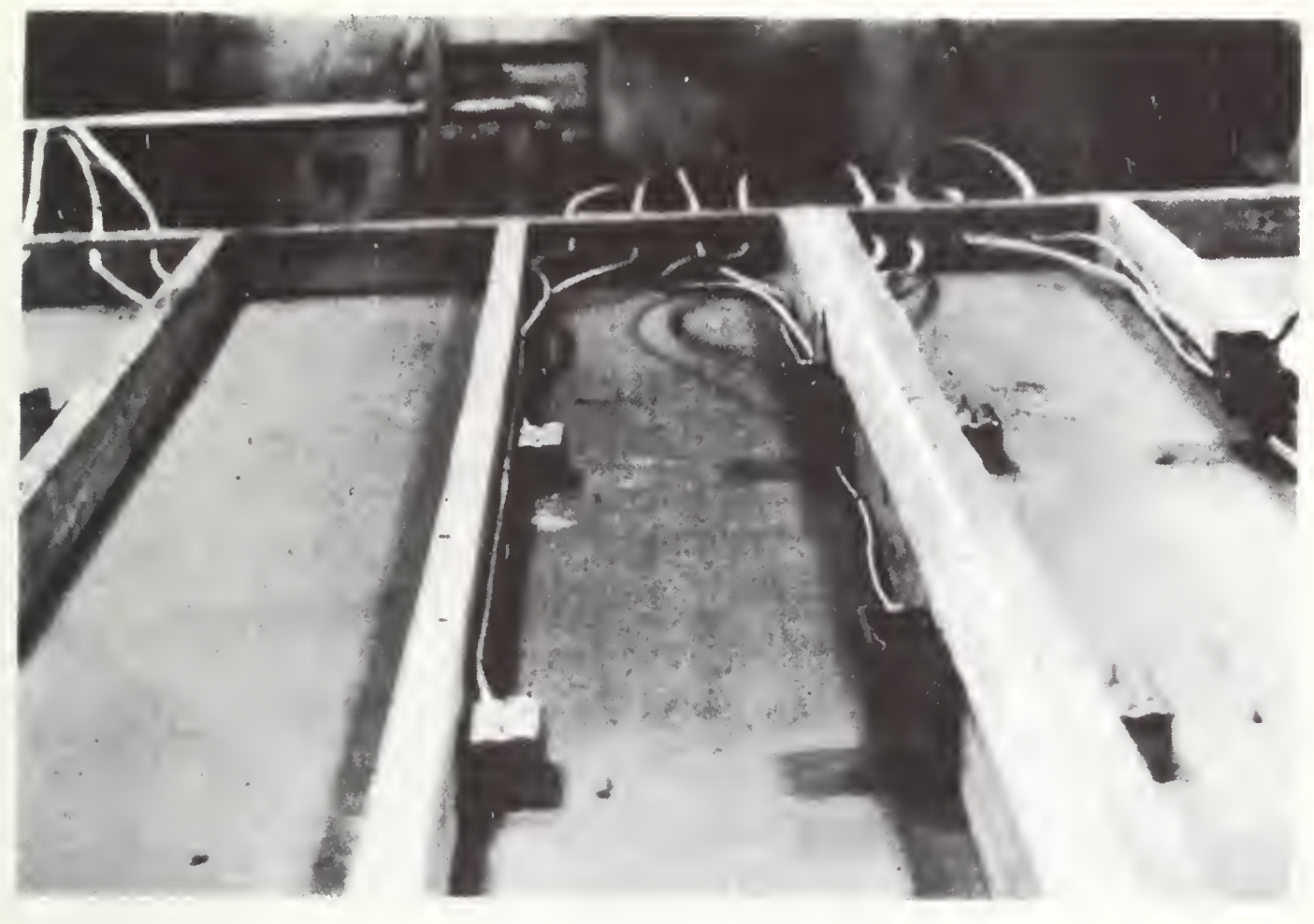

Figure 2. Wall No. I, steel electric boxes 


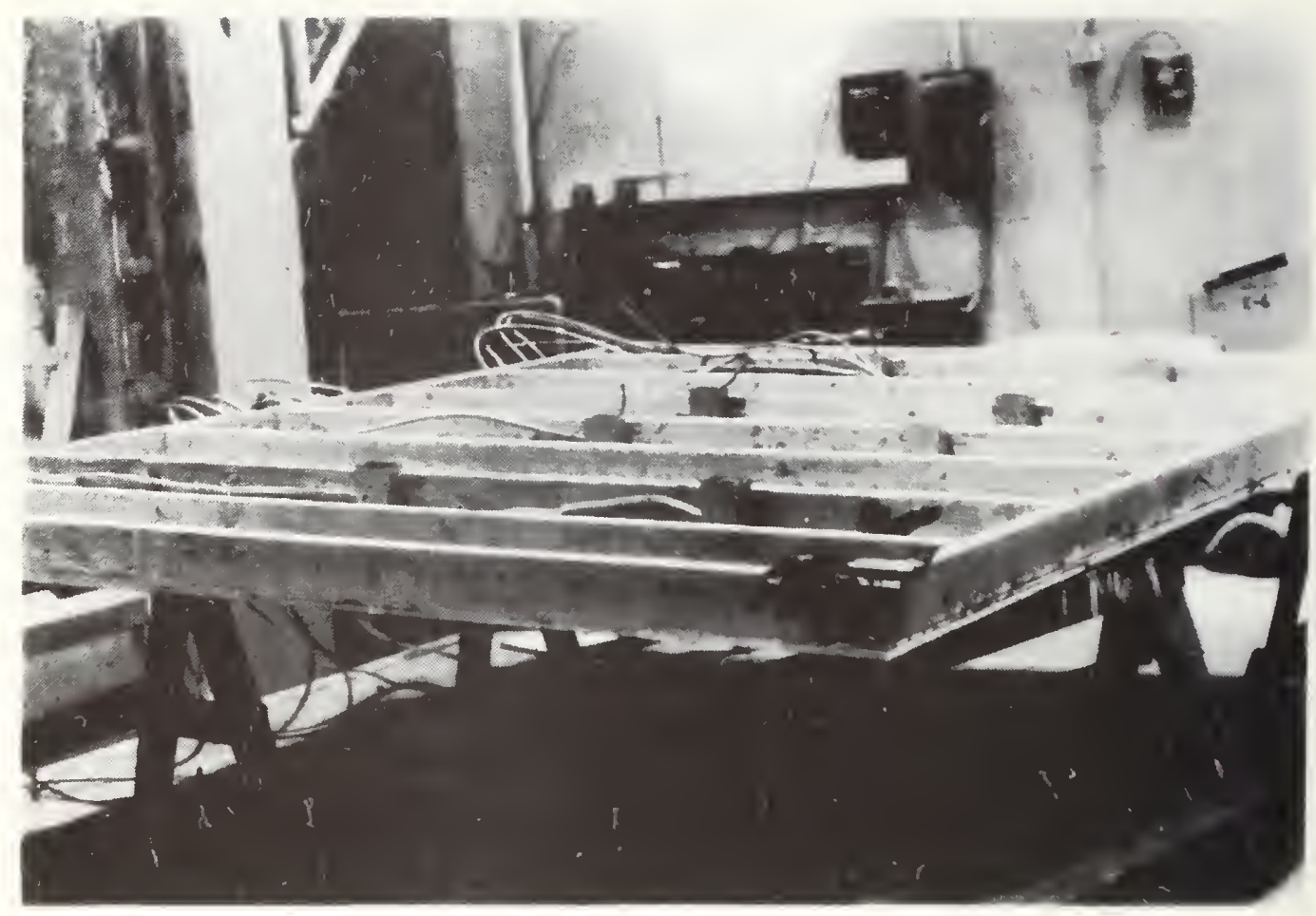

Figure 3. Wall No. 1 prior to inserting insulation 


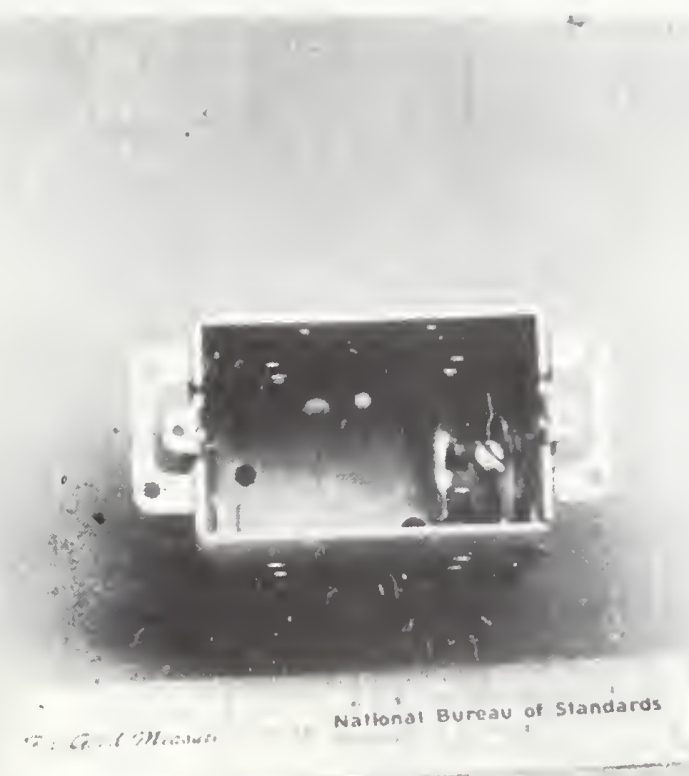

Figure 4. Electric box 


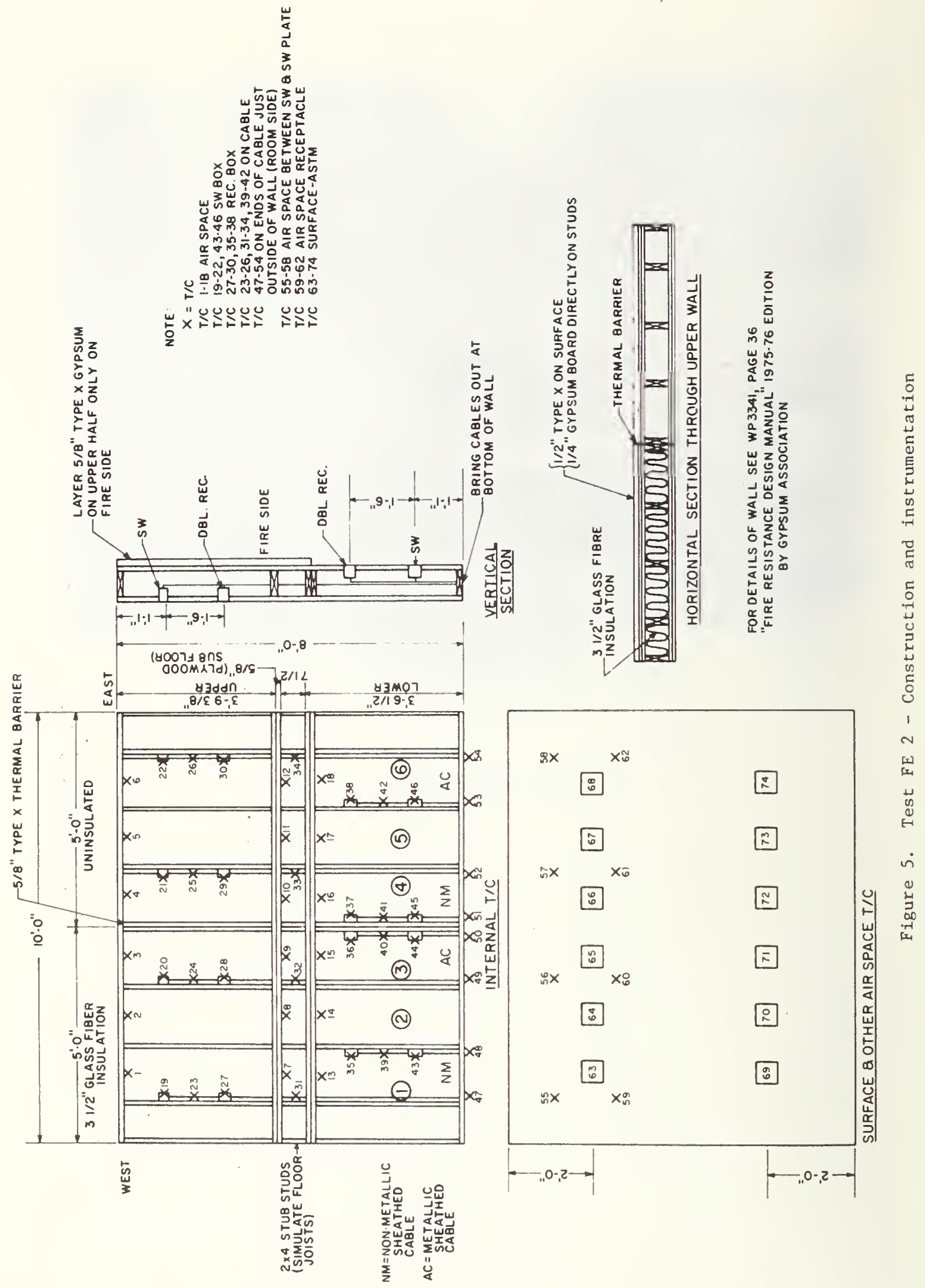




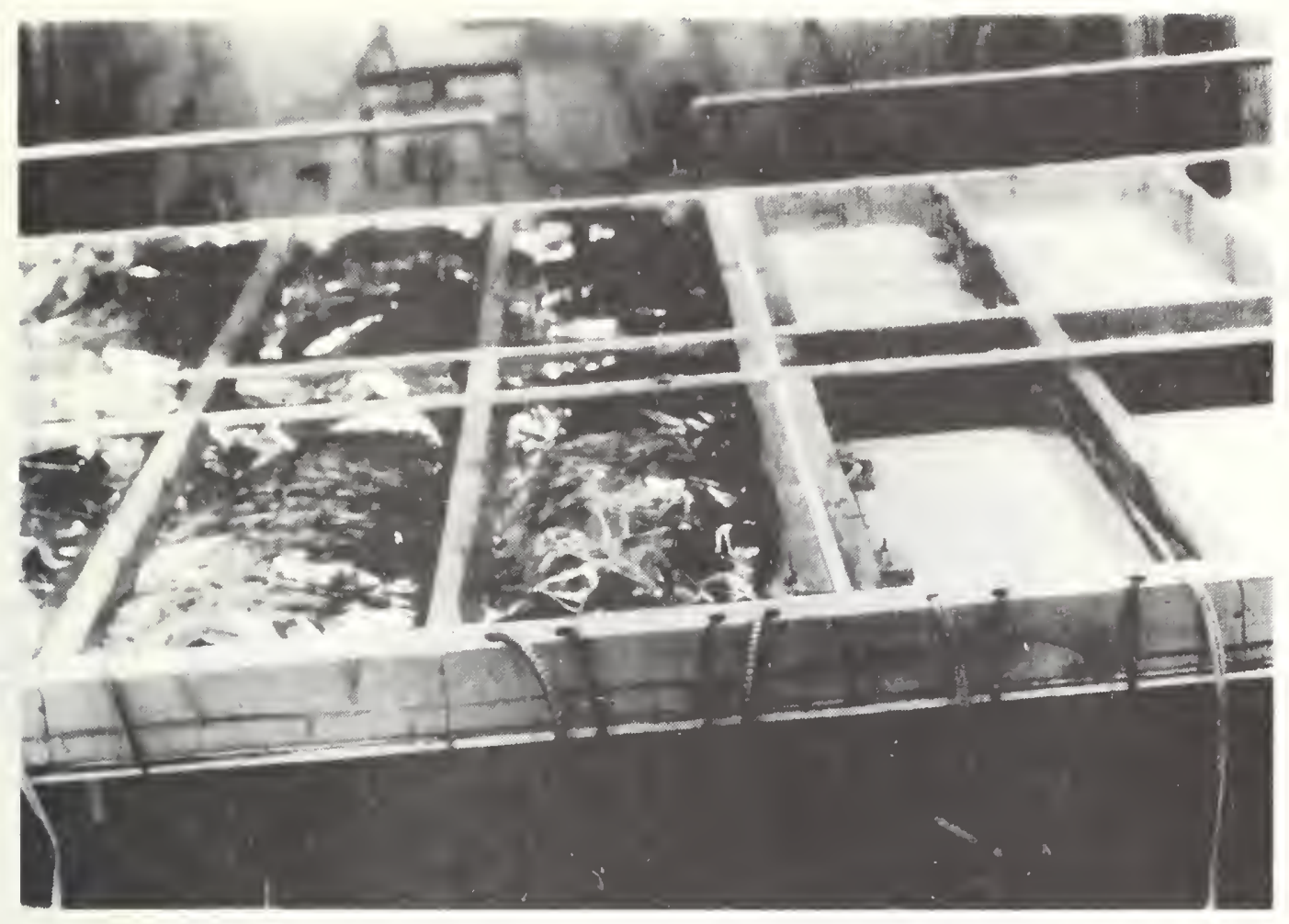

Figure 6. Wa11 2 prior, to applying second face

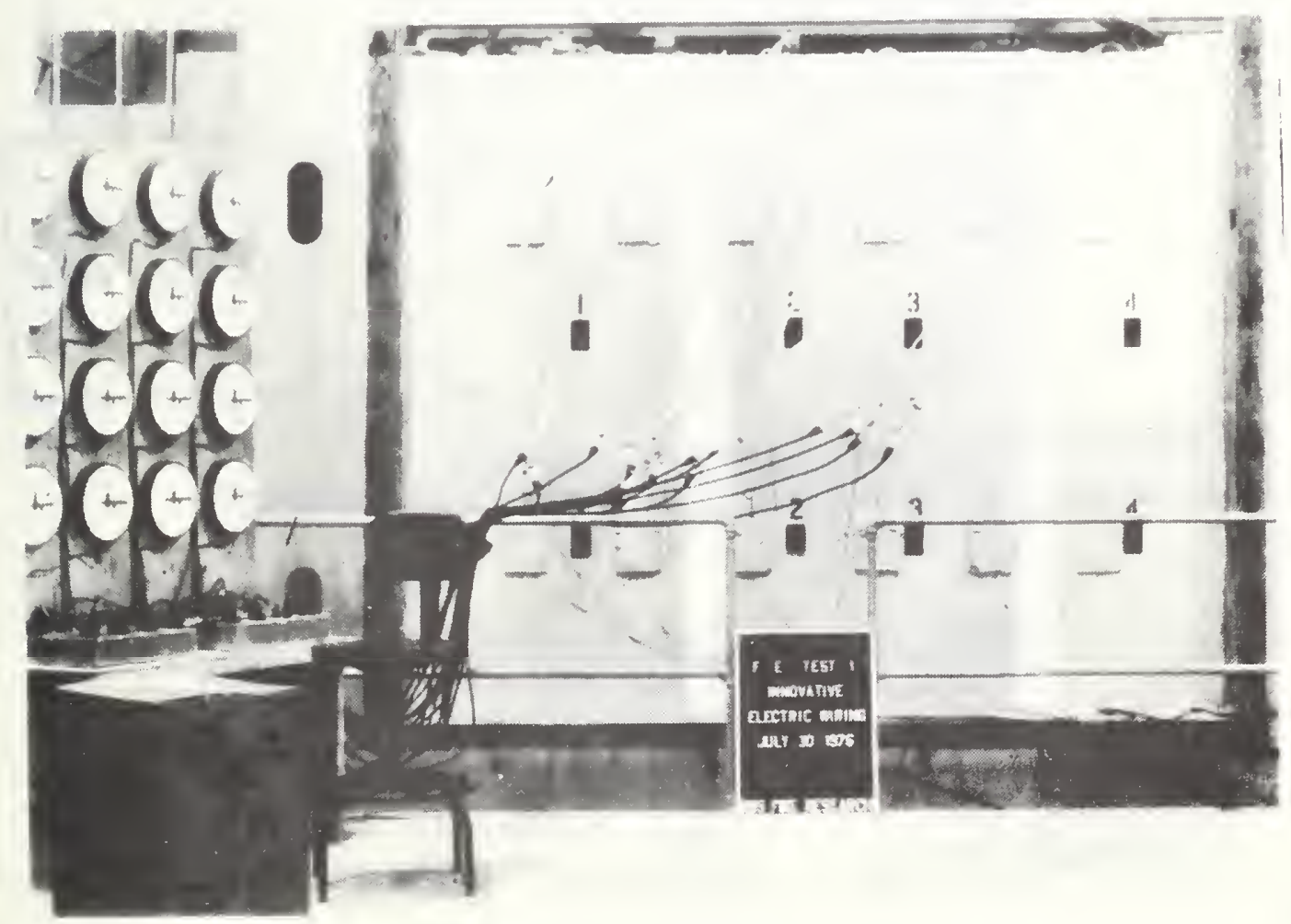

Figure 7. Wall 1 immediately prior to test. Note clocks on left. 


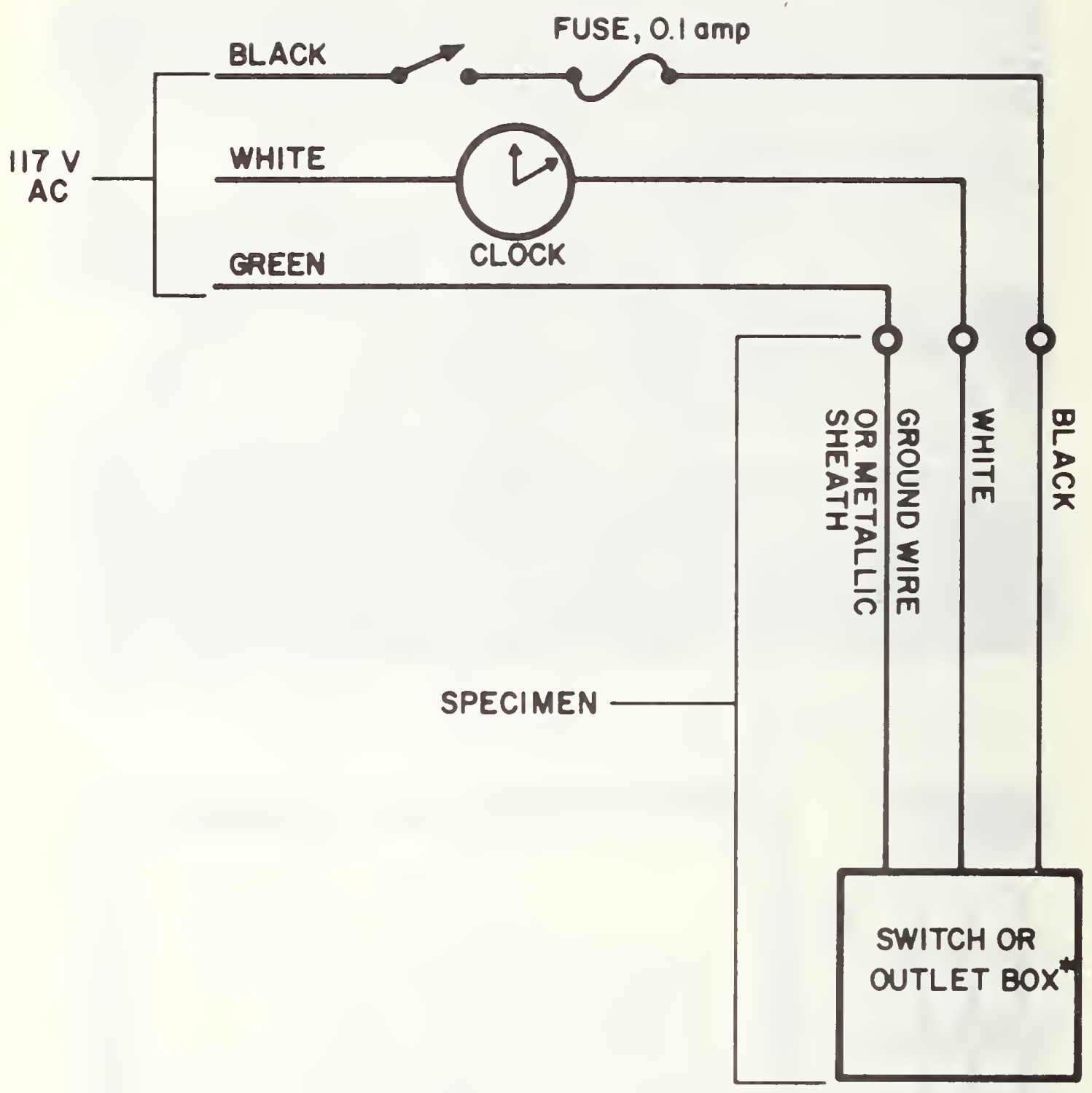

* Switch is closed. Receptable is shorted with o copper strap, .250 " wide by $.062^{\prime \prime}$ thick

Figure 8. Wiring diagram for electric clocks 


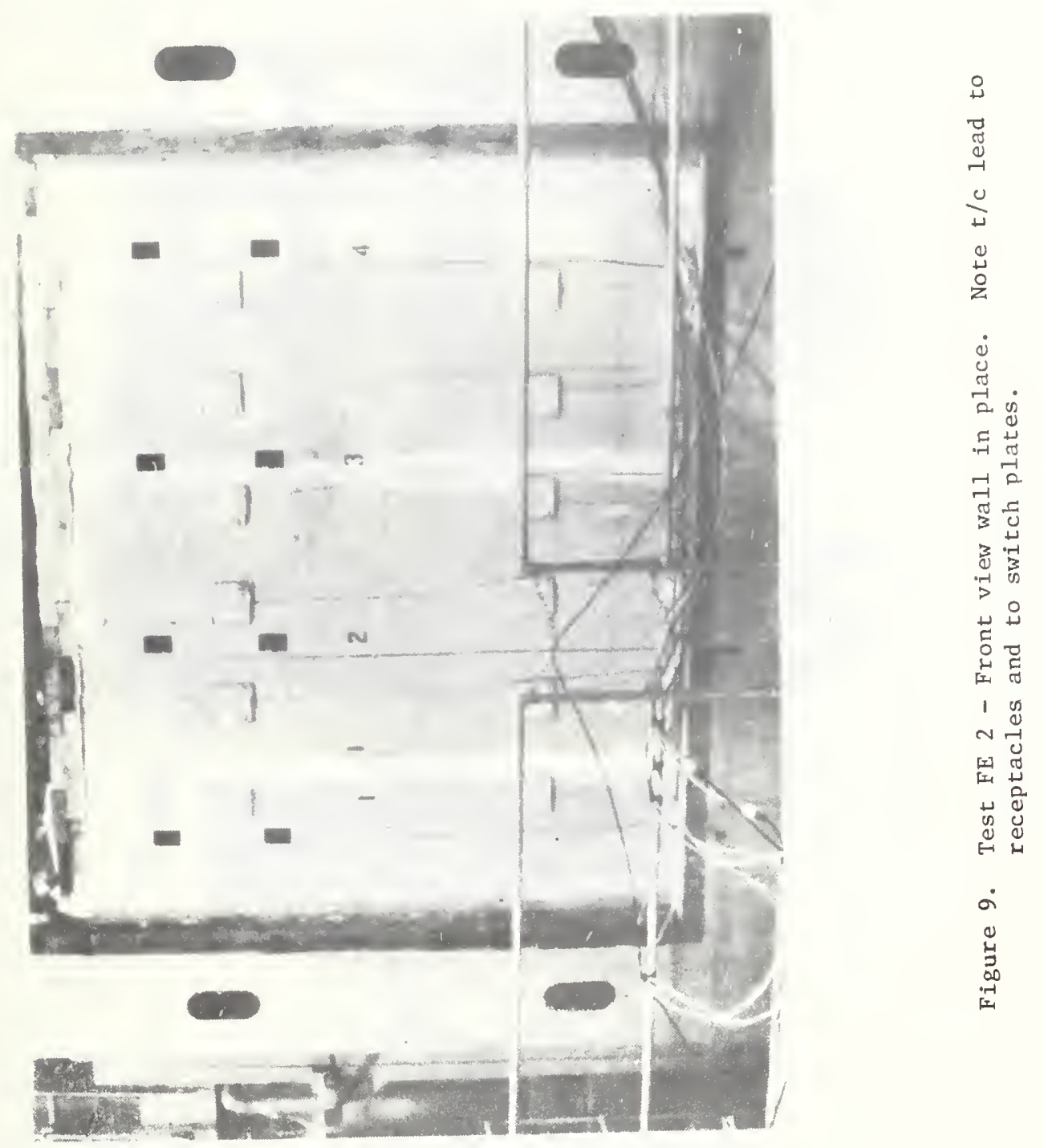




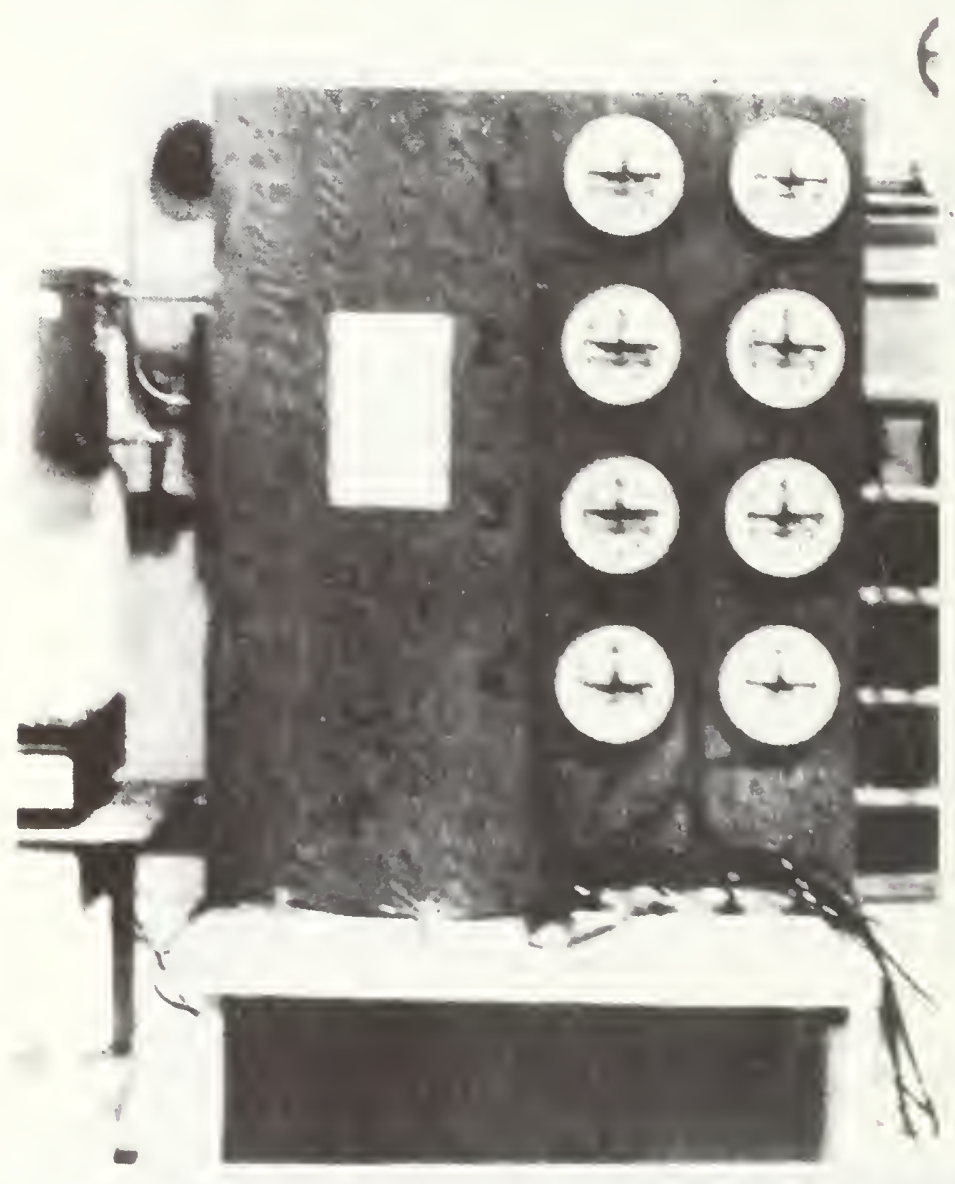

Figure 10. Test FE 2 - Clock setup 


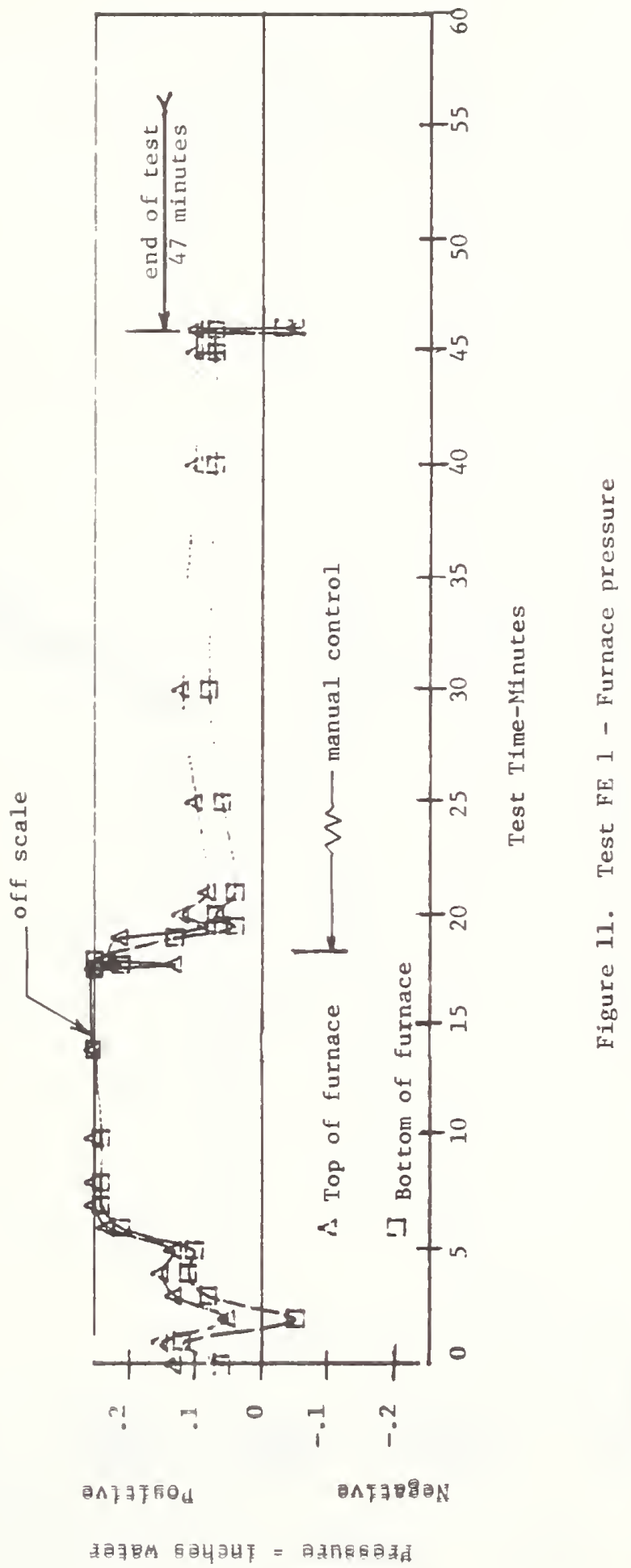




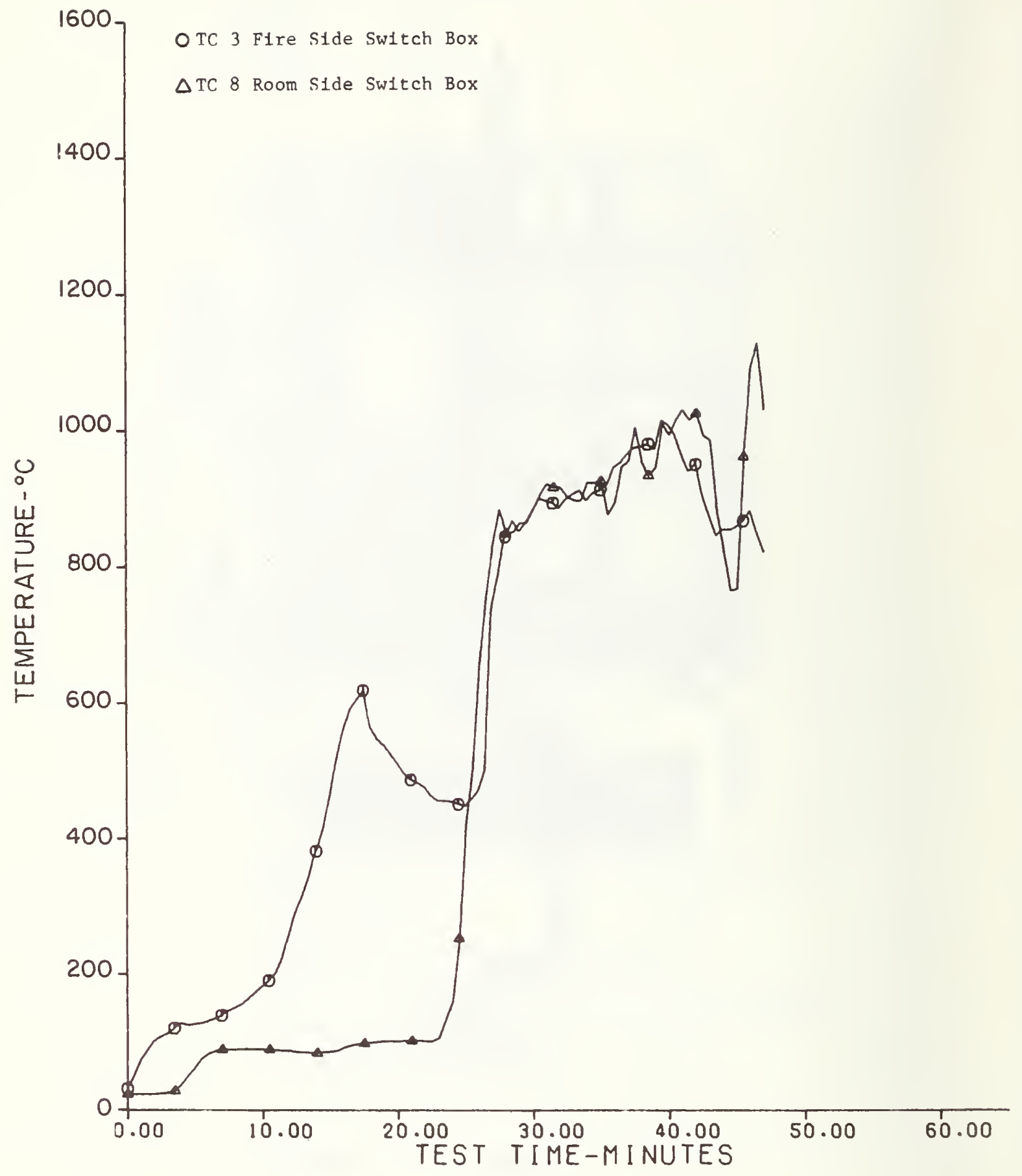

Figure 12. Test FE 1 - Insulated wall NM switch box temperatures 


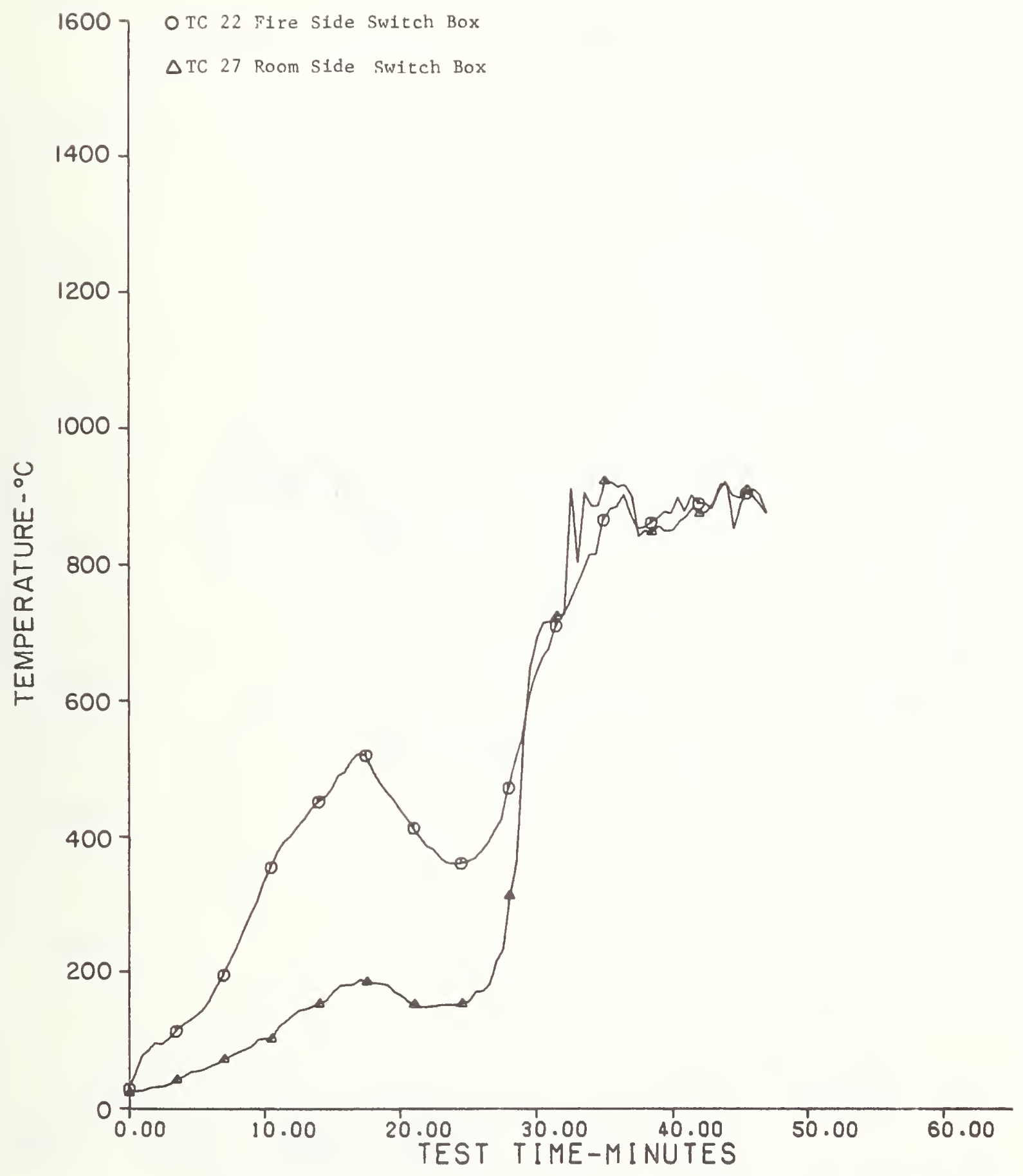

Figure 13. Test FE 1 - Uninsulated wall NM switch box temperatures 


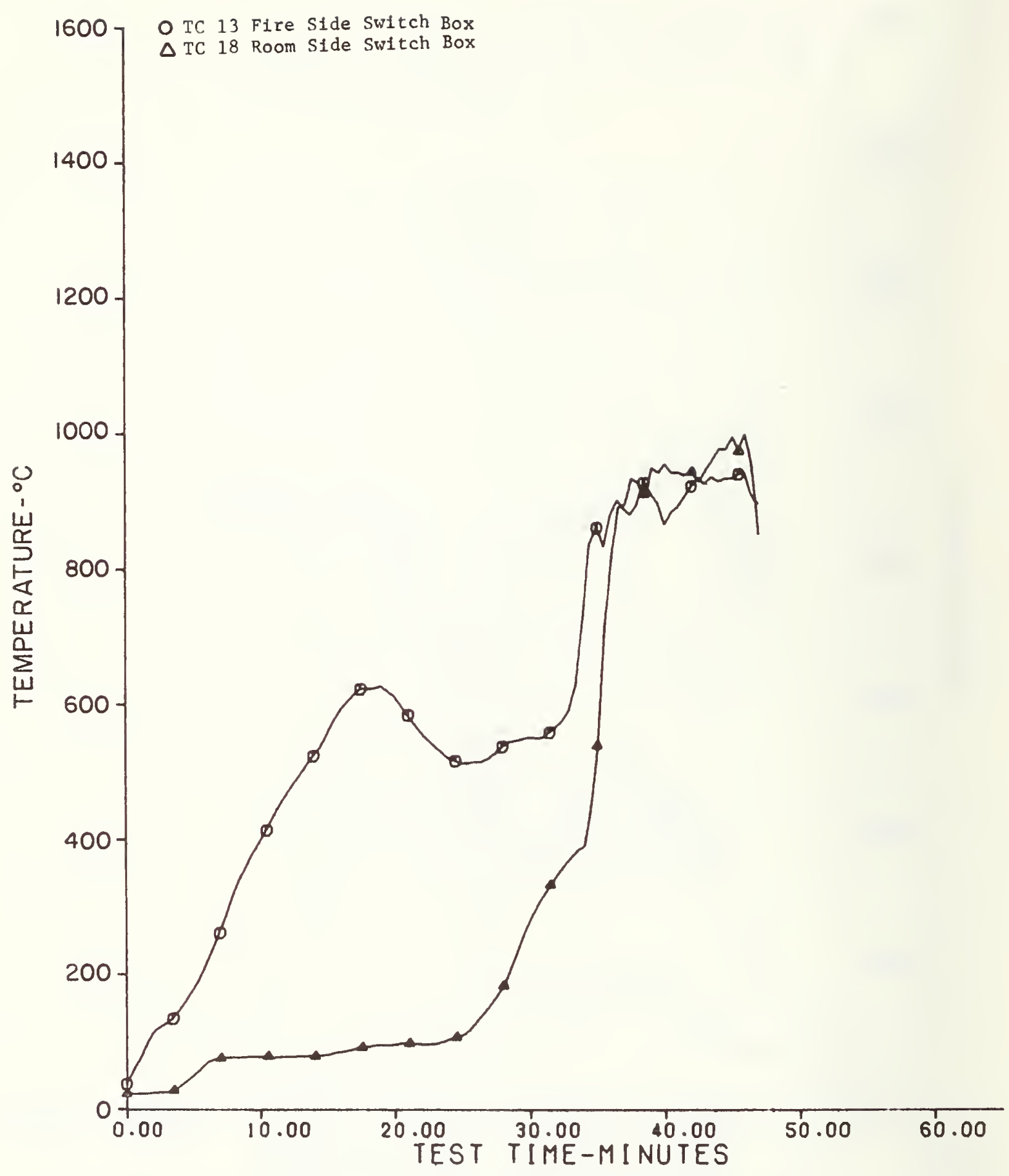

Figure 14. Test FE 1 - Insulated wal1 AC switch box OTC $13 \triangle$ TC 18 temperatures 


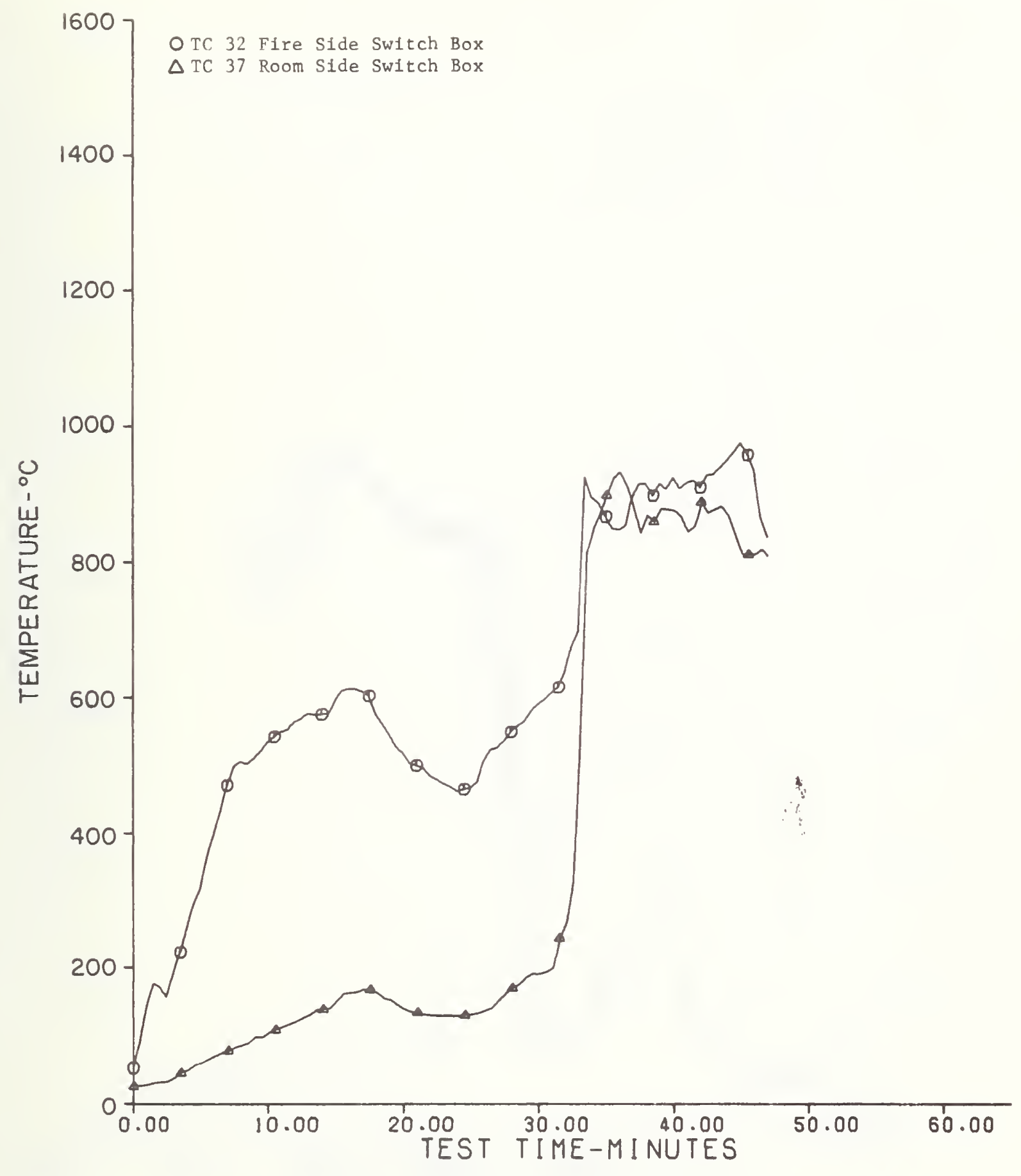

F1gure 15. Test FE 1 - Uninsulated wall AC switch box temperatures

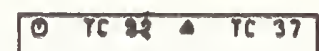
te 


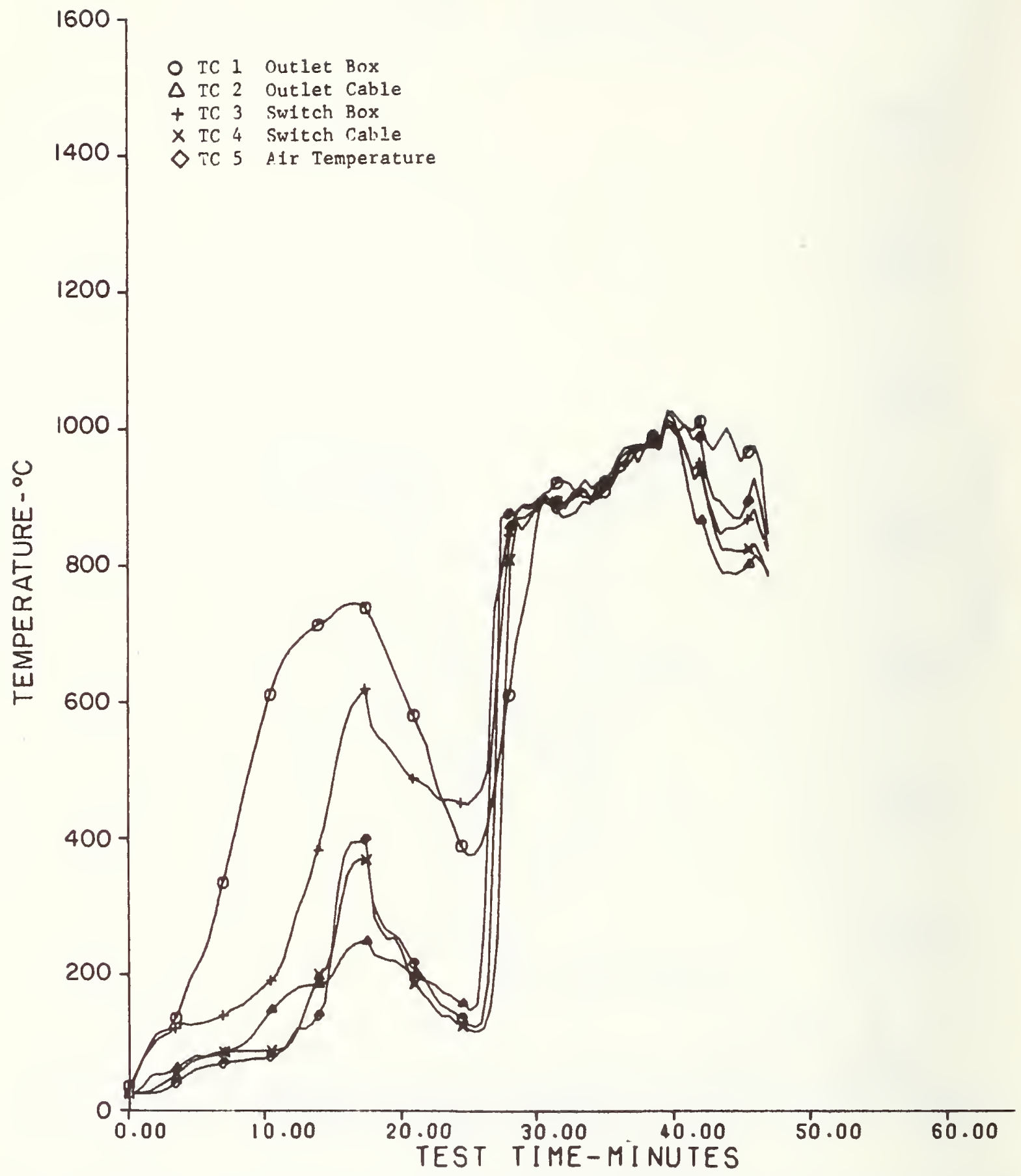

Figure 16. Test FE 1 - Insulated wall NM fire side temperatures 


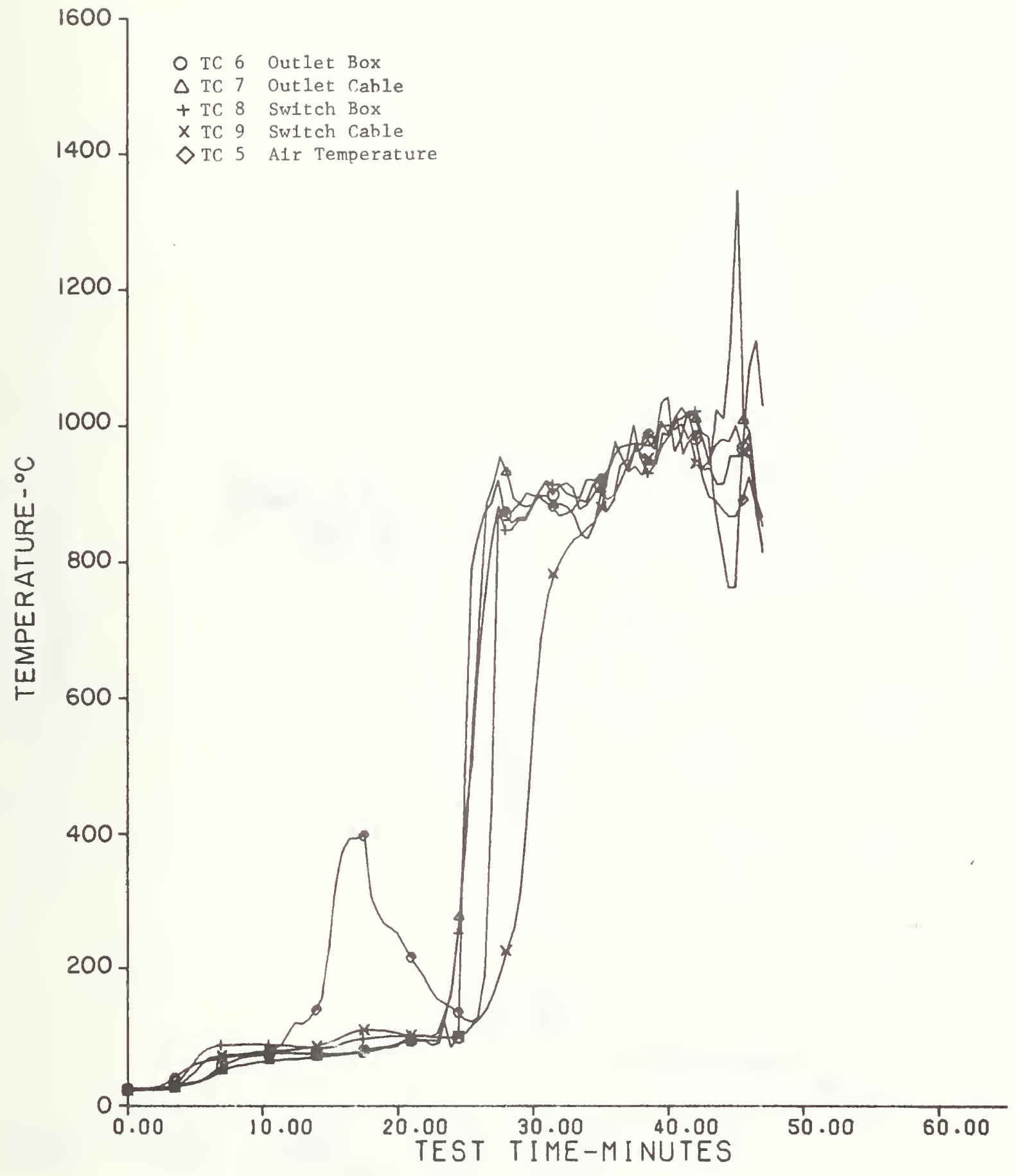

Figure 17. Test FE 1 - Insulated wall NM room side
temperatures \begin{tabular}{lllllll|}
\hline 0 & $T C$ & 6 & $A$ & $T C$ & $?$ \\
+ & $T C$ & 8 & $x$ & $T C$ & 9 \\
0 & $T C$ & 5 & & & \\
\hline
\end{tabular} 


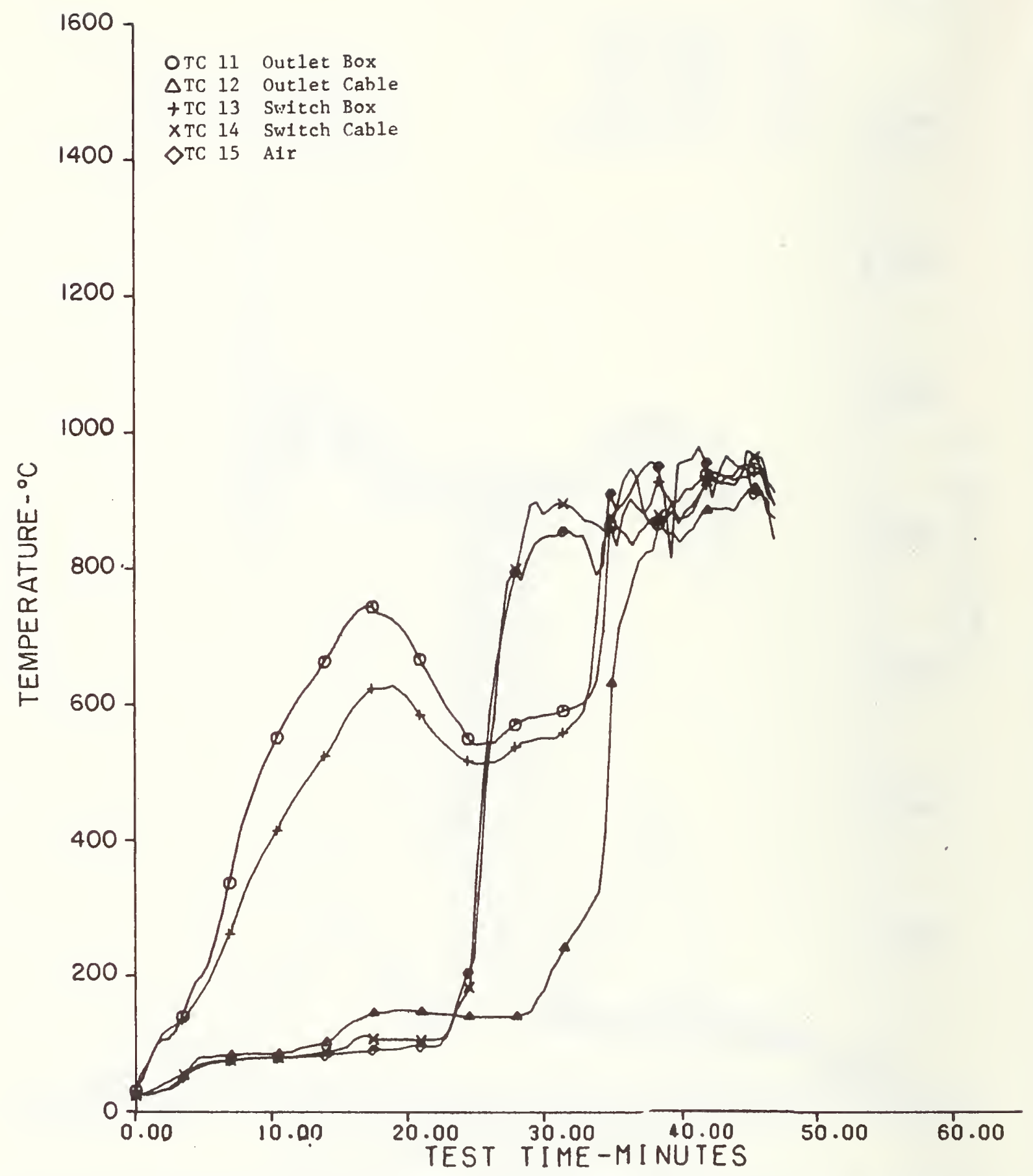

Figure 18. Test FE 1 - Insulated wall AC fire side temperatures 


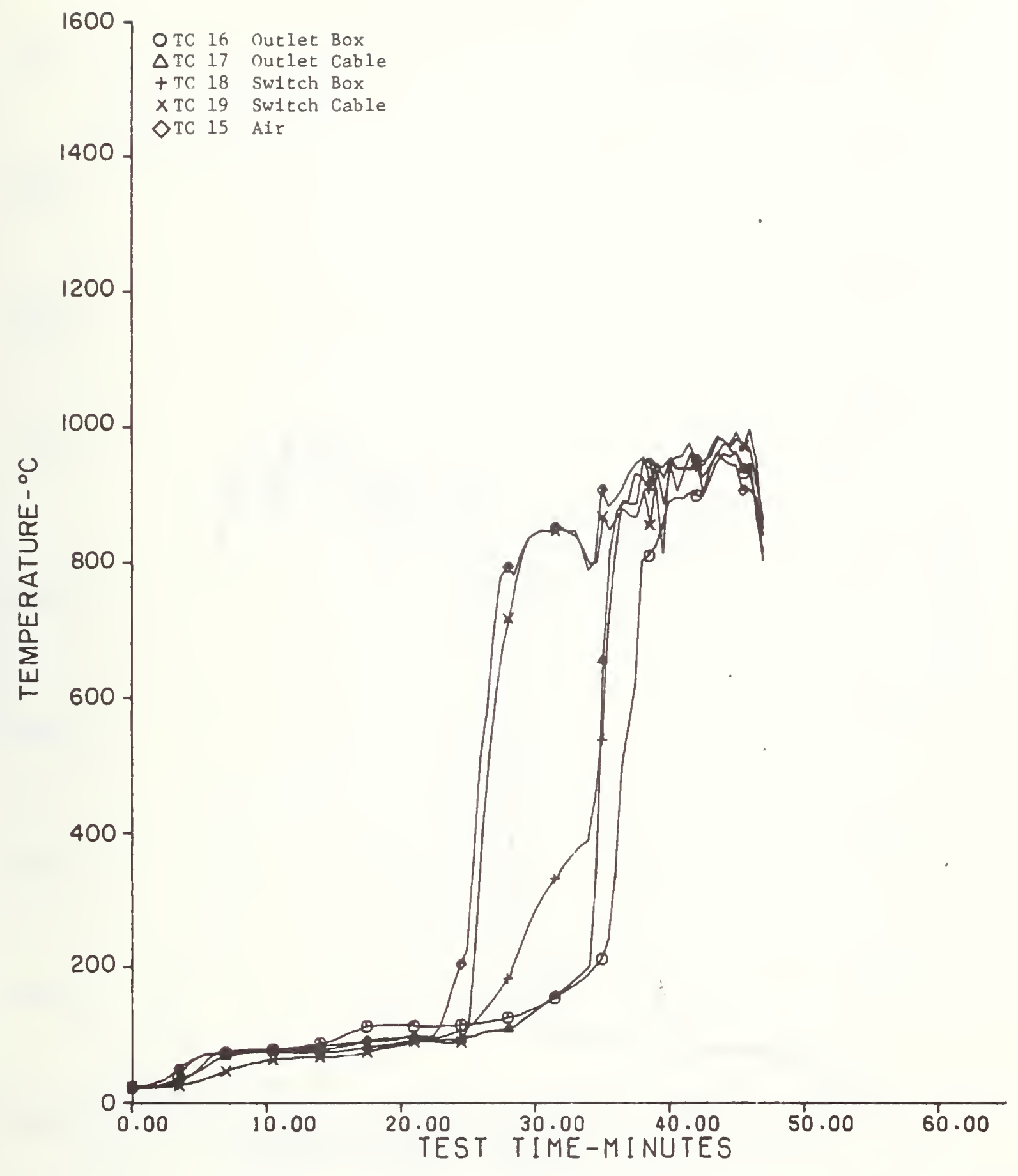

Figure 19. Test FE 1 - Insulated wall AC room side temperatures 


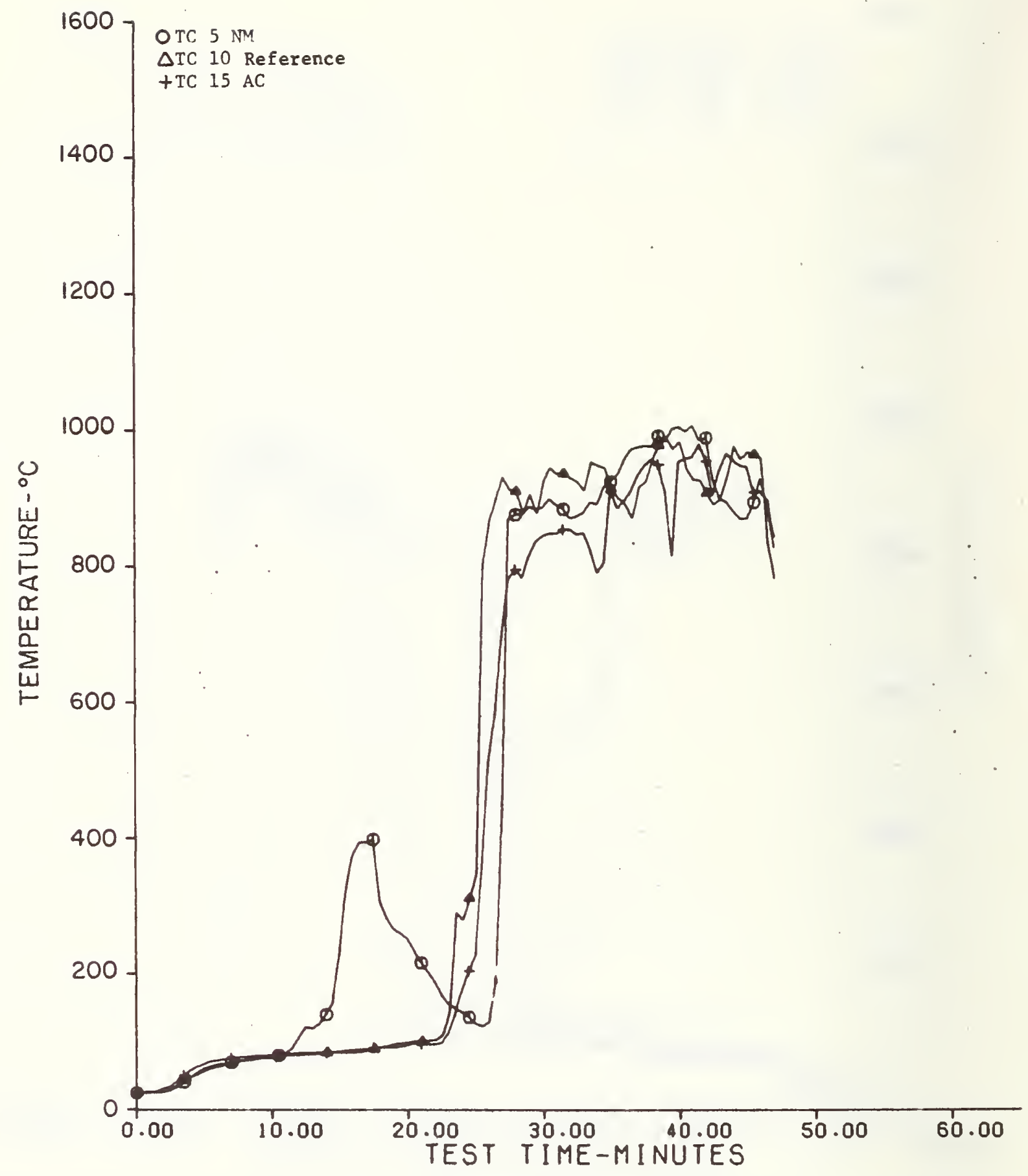

Figure 20. Test FE 1 - A1r temperatures insulated wal1 


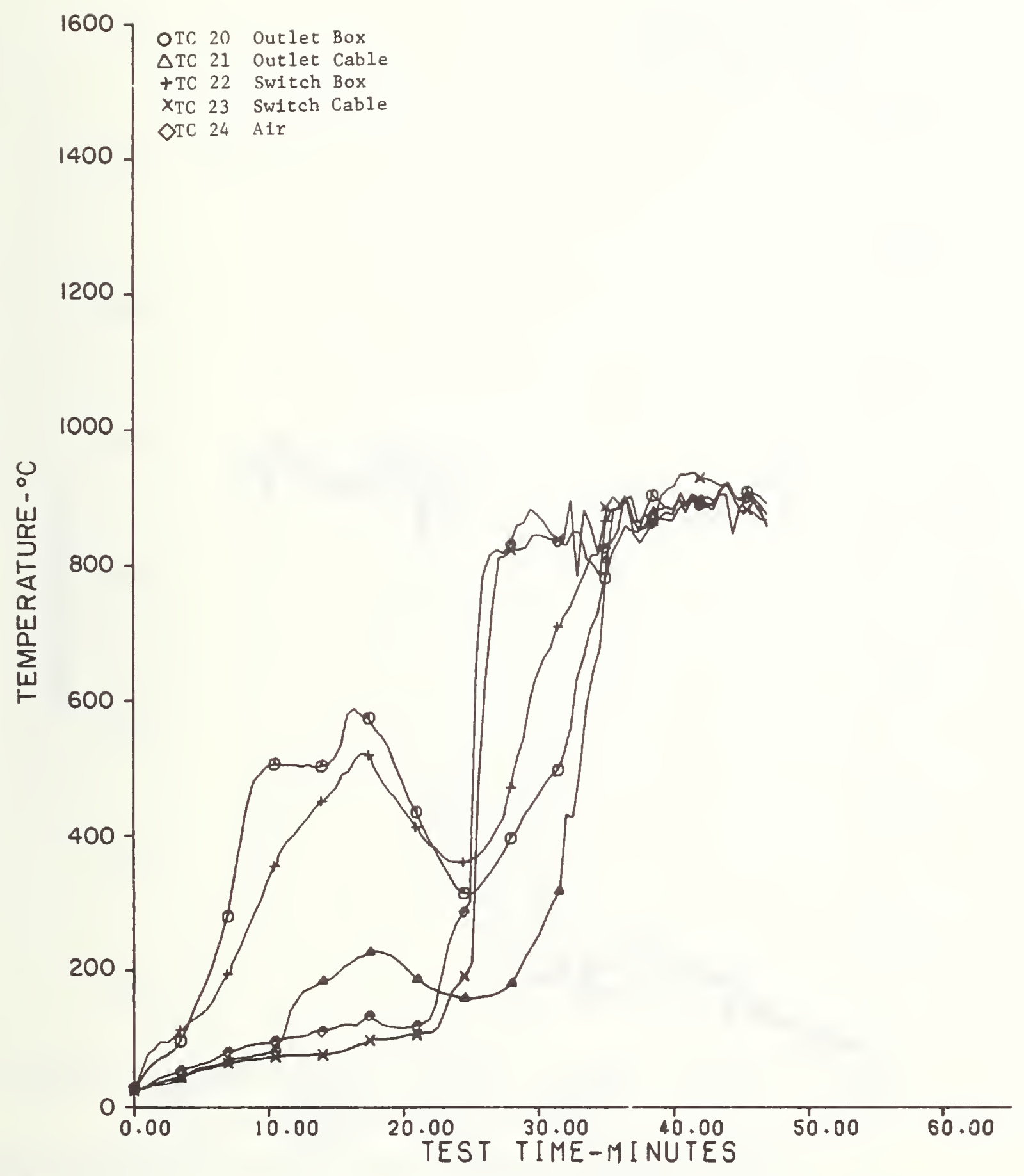

Figure 21. Test FE 1 - Uninsulated wall MM fire side temperatures

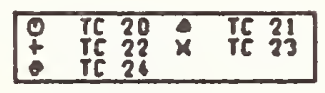




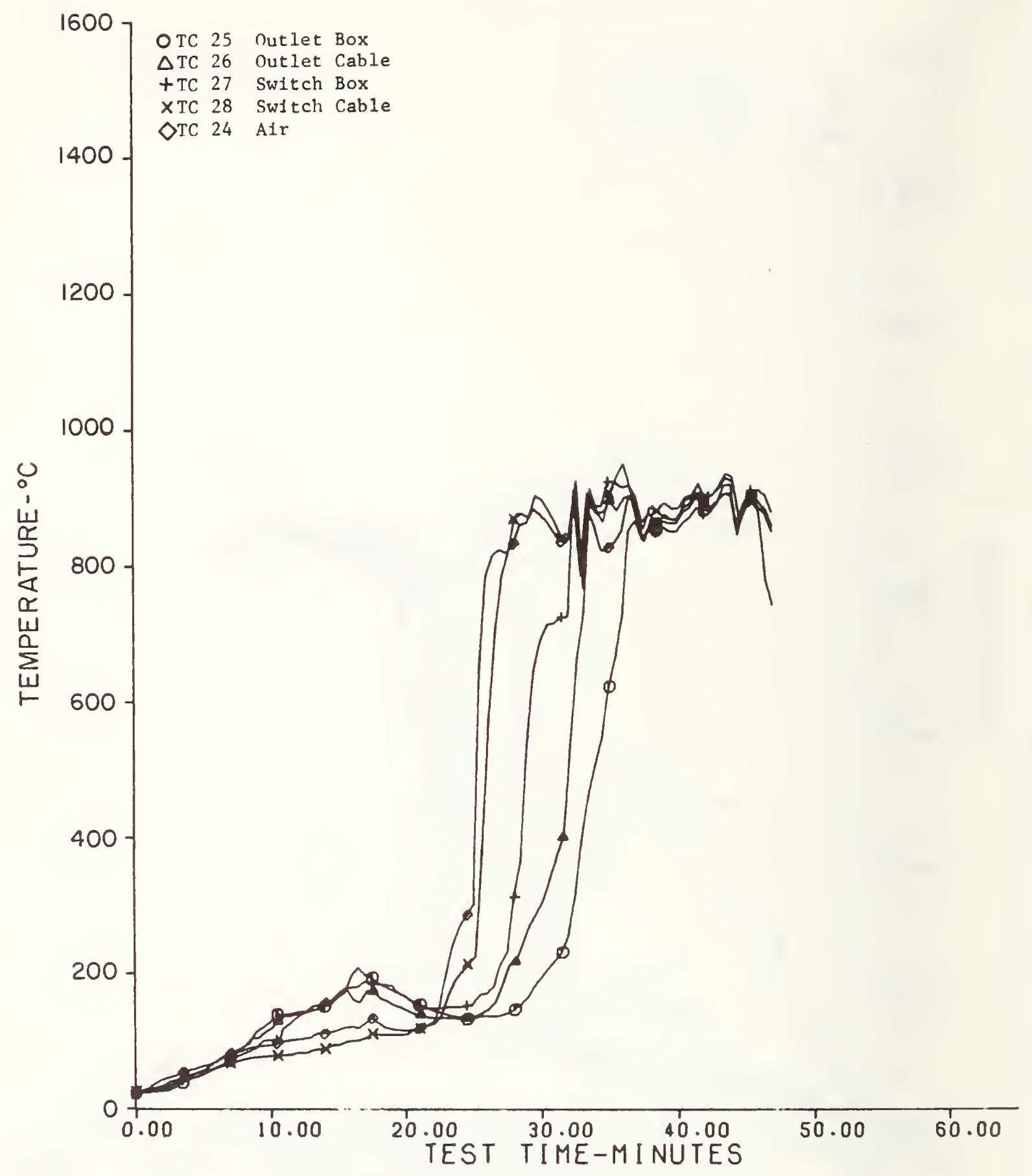

Figure 22. Test FE 1 - Uninsulated wall NM room side temperatures 


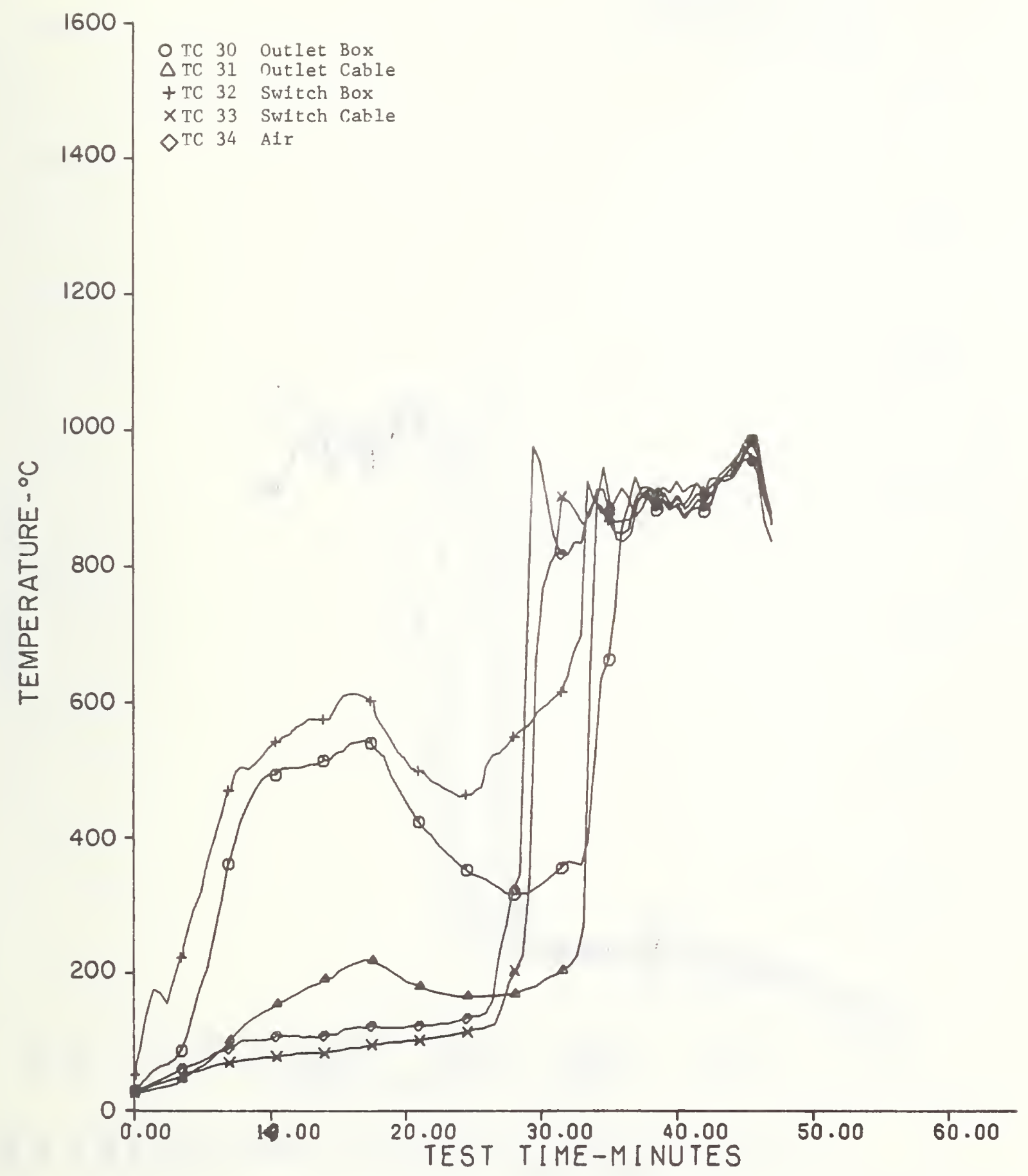

Figure 23. Test FE 1 - Uninsulated wall AC fire side temperatures 


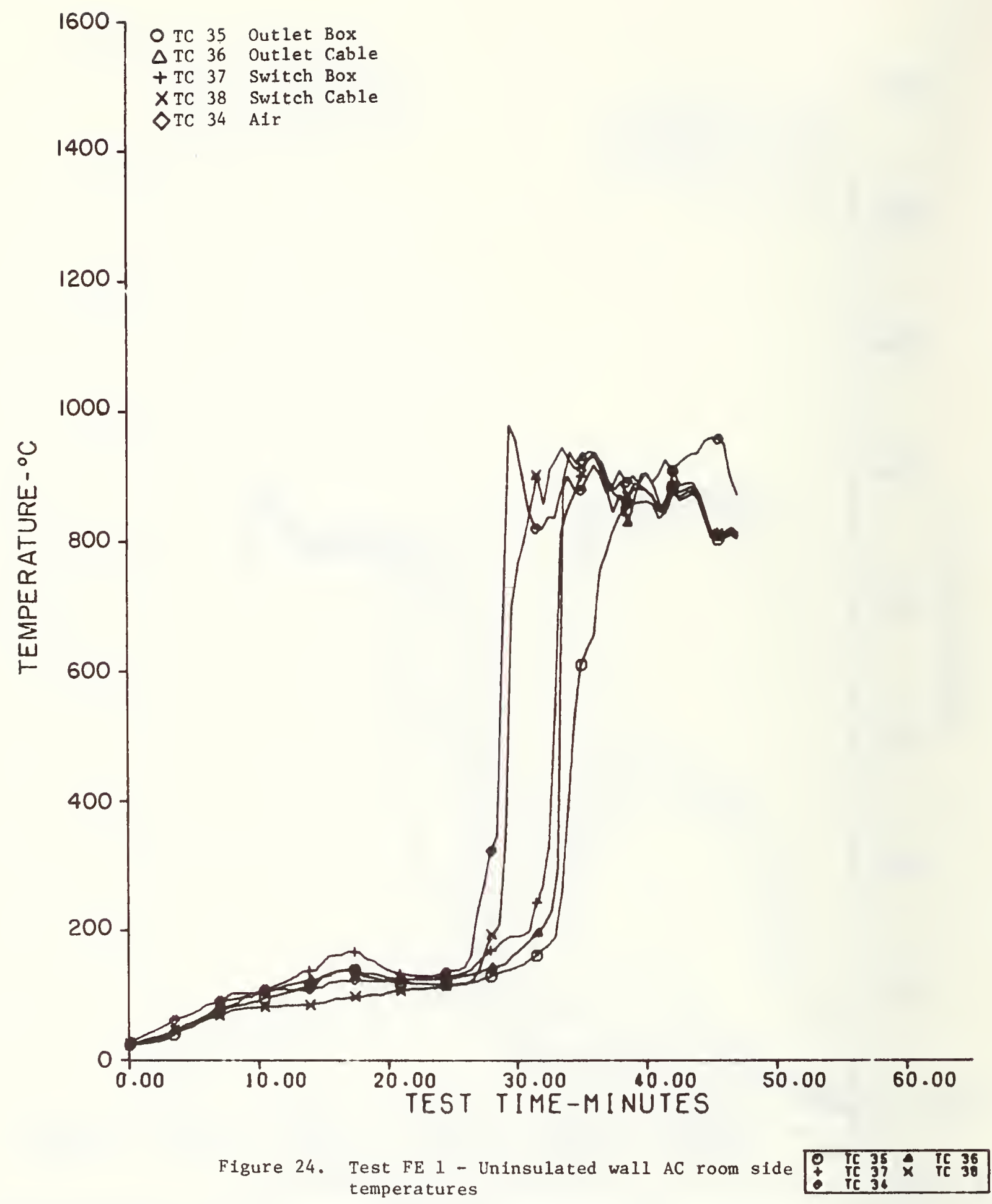




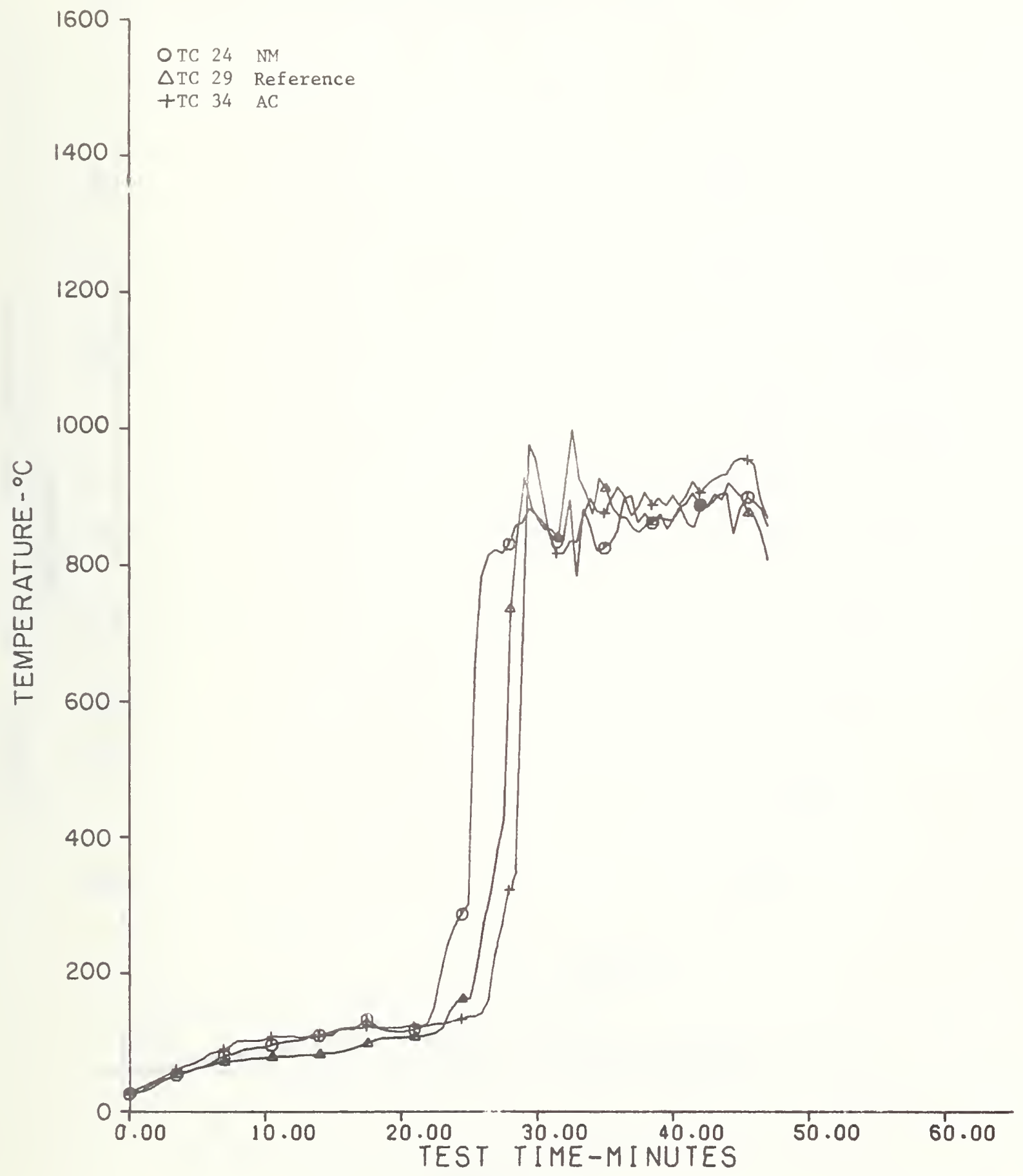

Figure 25. Test FE 1 - Uninsulated wall air space temperatures 


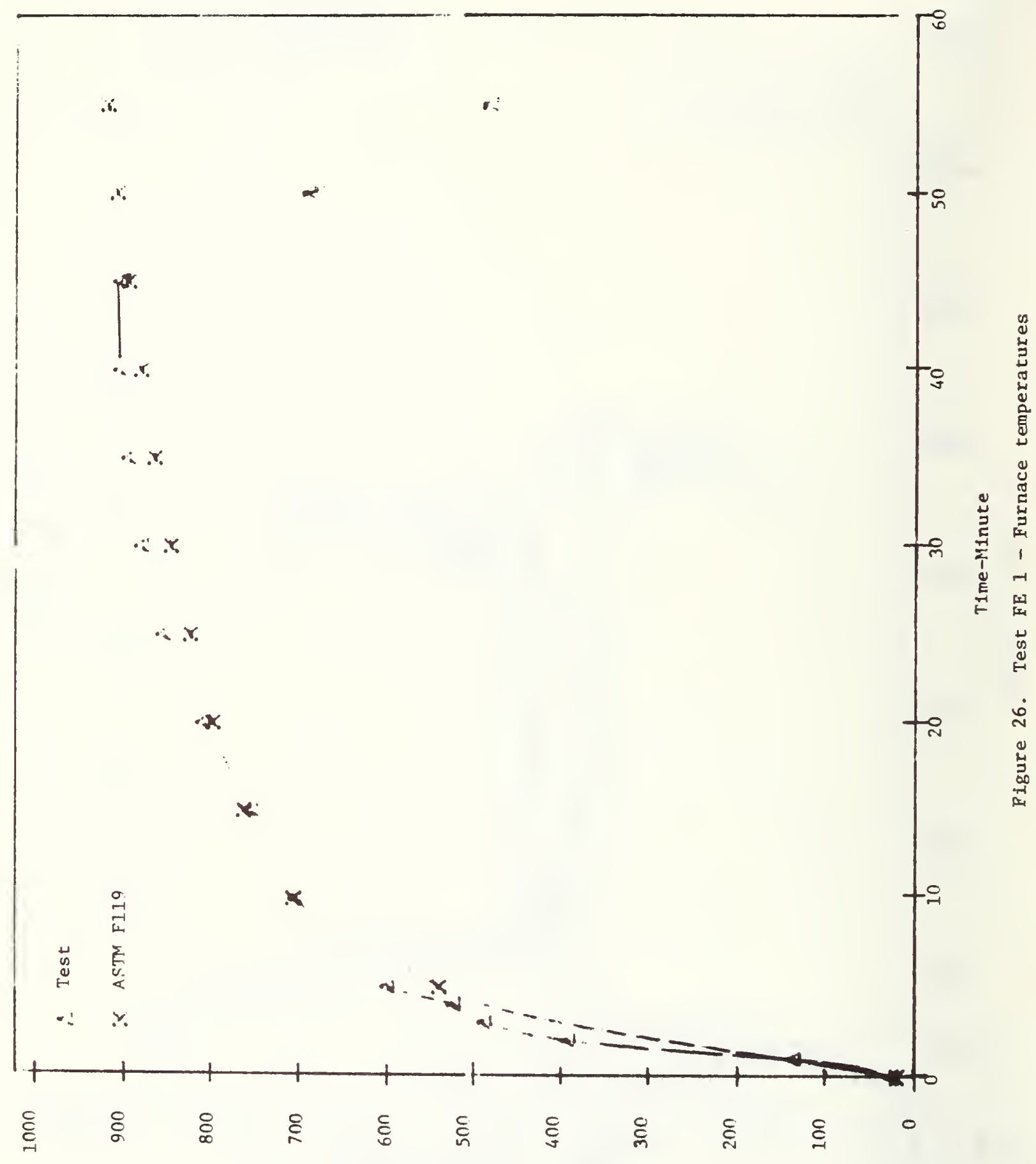

J yacI-duaI 


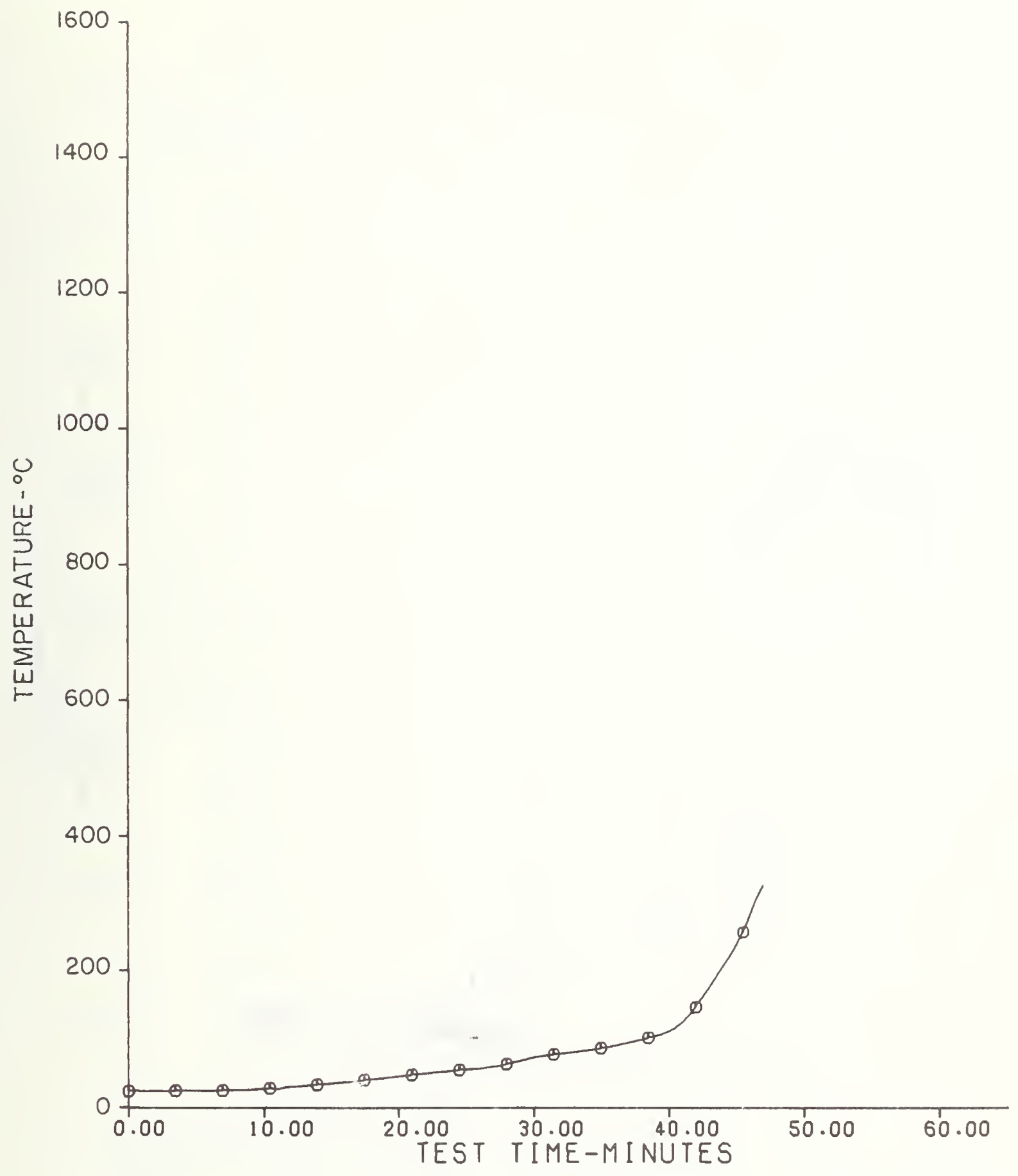

Figure 27. Test FE 1 - Average unexposed surface temperature away from electric fittings 


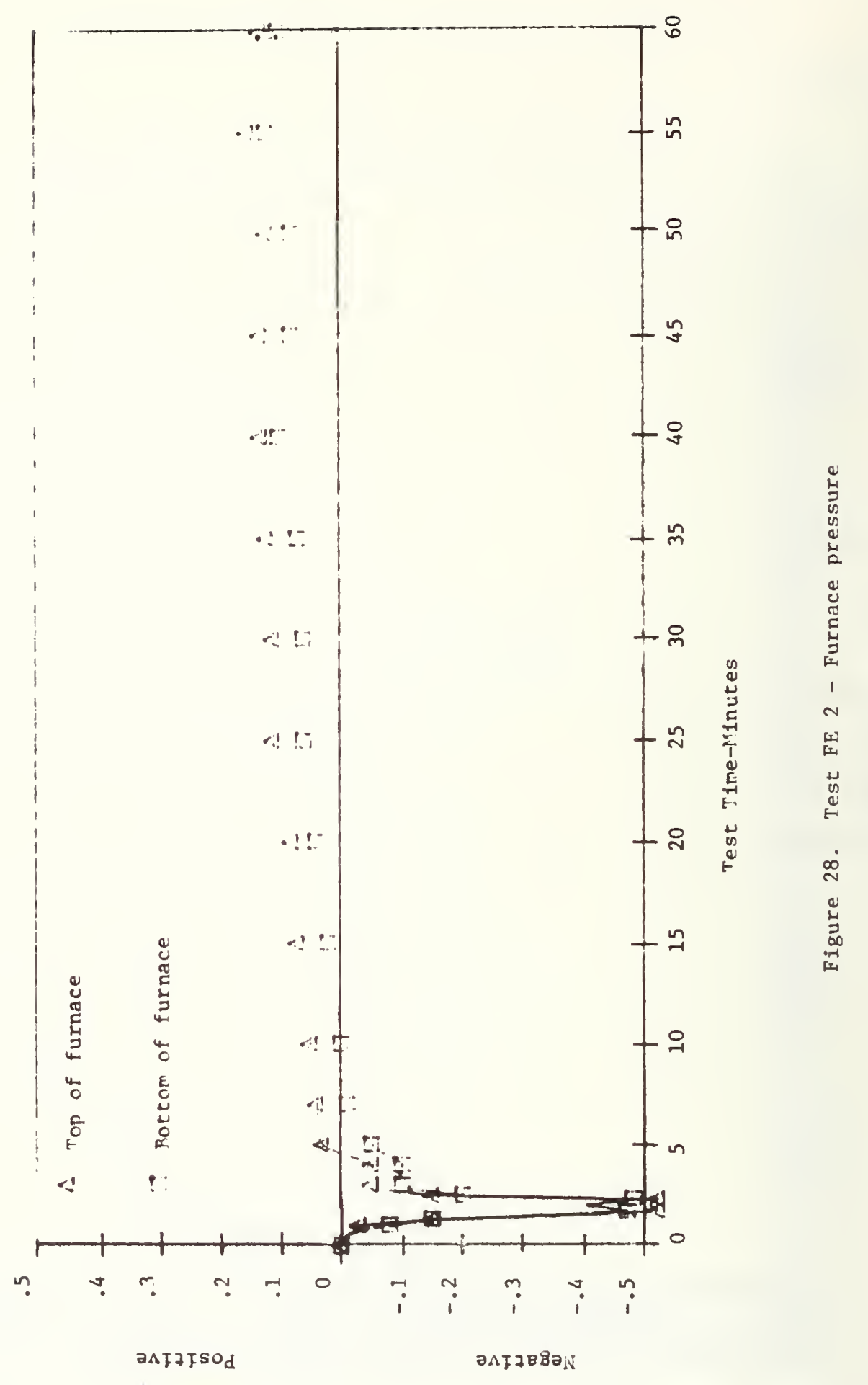

Iaว $E_{1}$ sayวuI-aIns6a $\alpha_{d}$ 


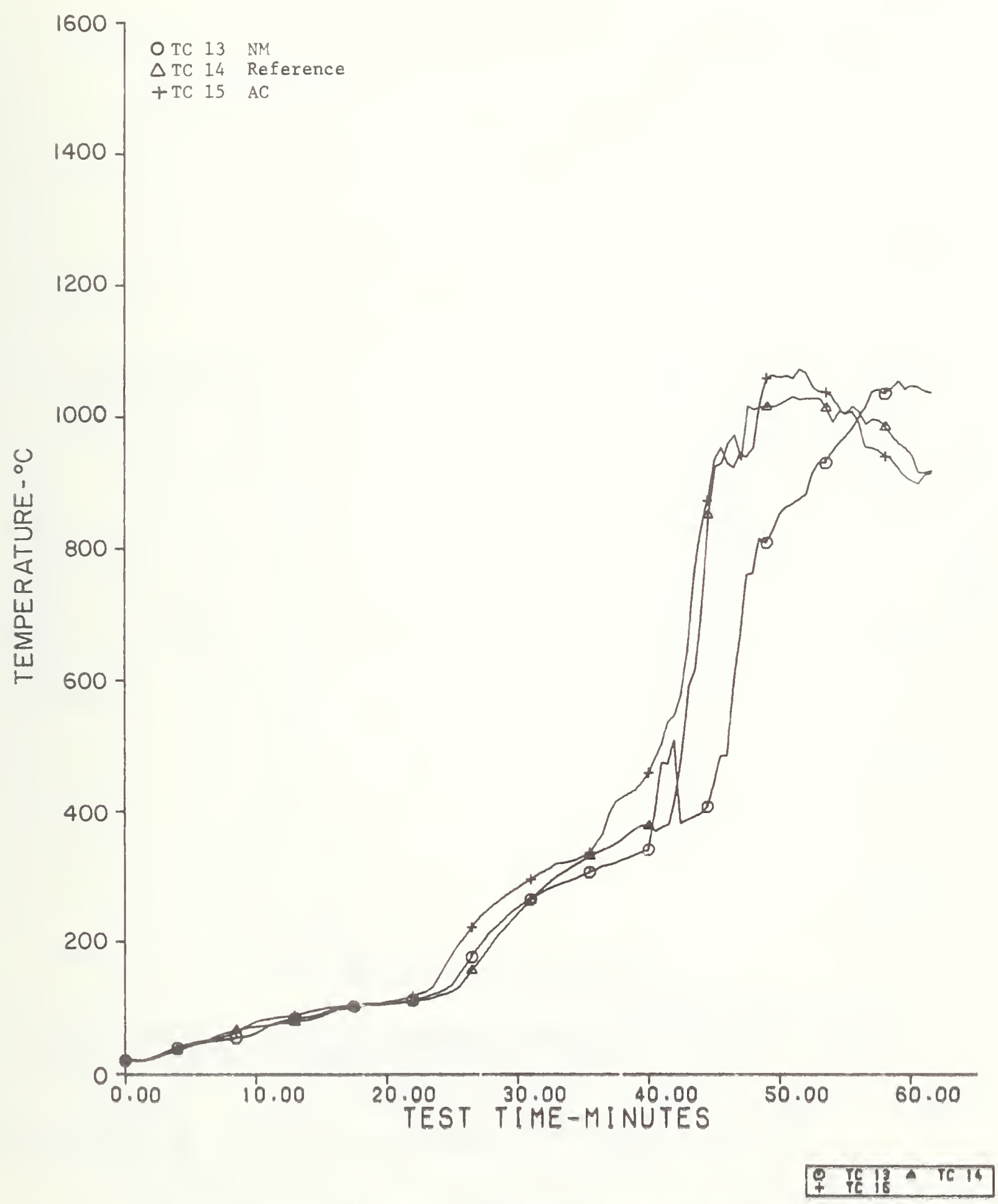

F1gure 29. Test FE 2 - Air temperatures lower insulated wall 


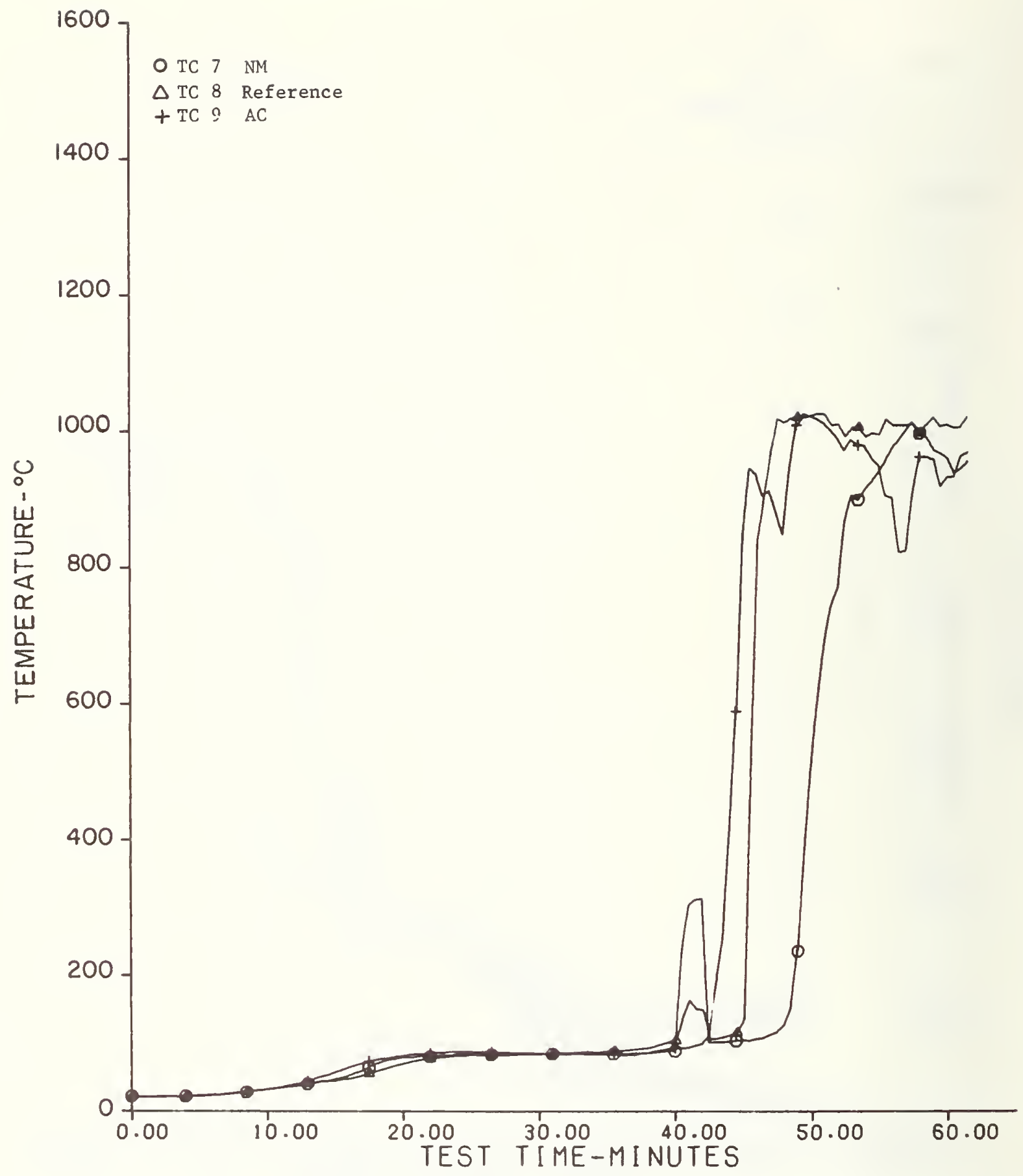

Figure 30. Test FE 2 - Air temperatures floor space insulated wall

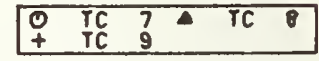




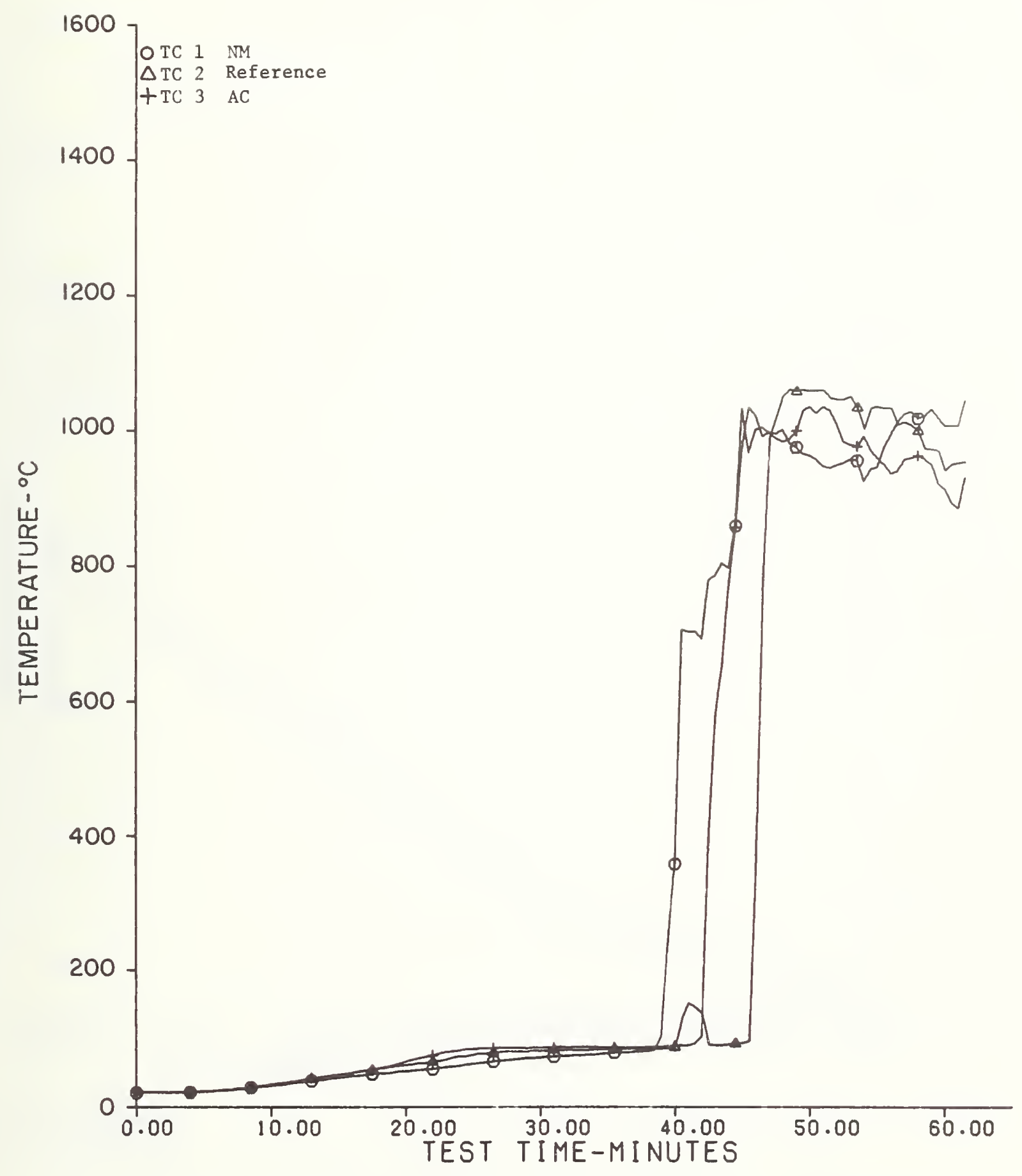

Figure 31. Test FE 2 - Air temperatures upper insulated wal1

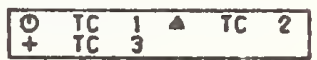




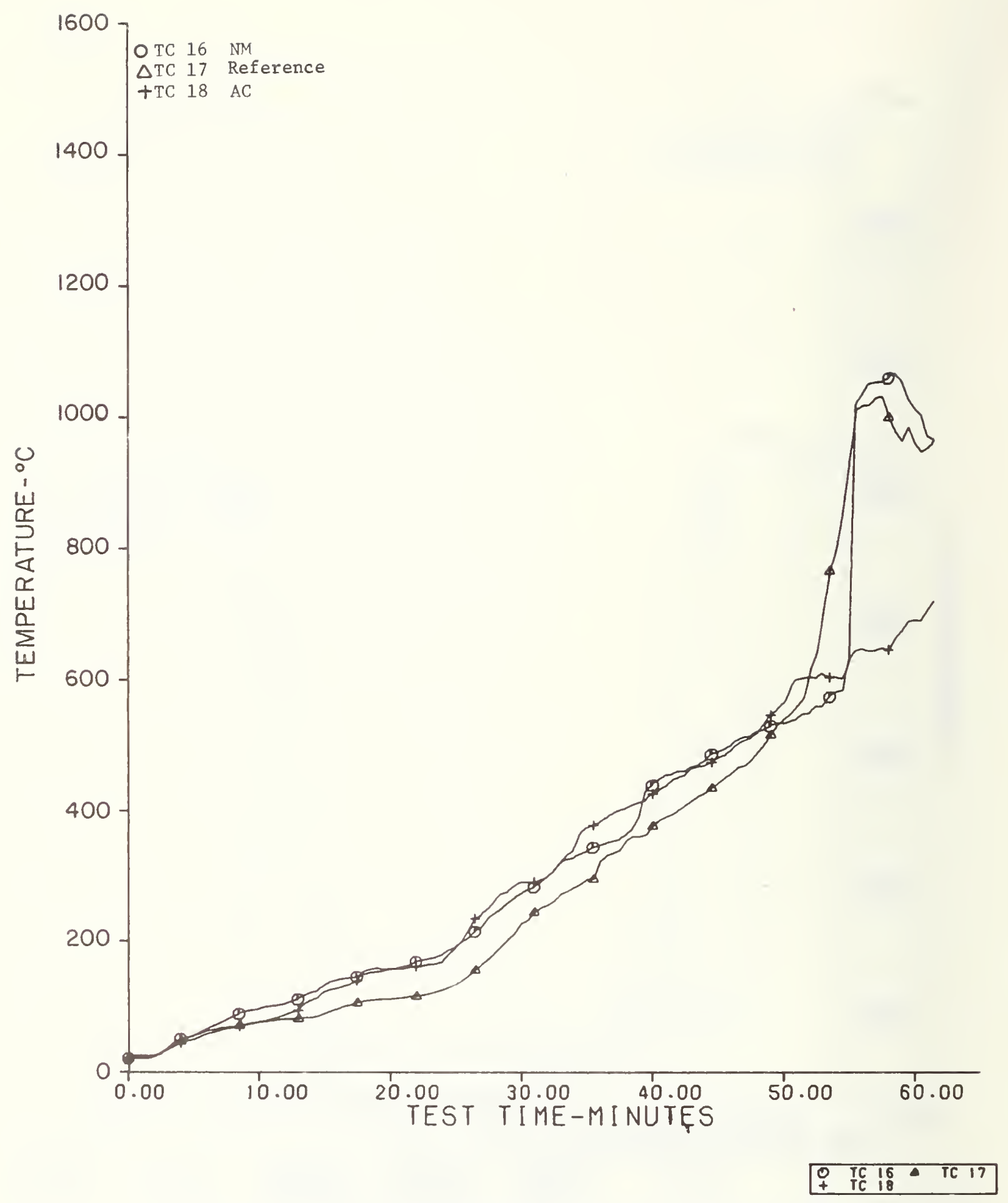

Figure 32. Test FE 2 - Air temperatures lower uninsulated wa11 


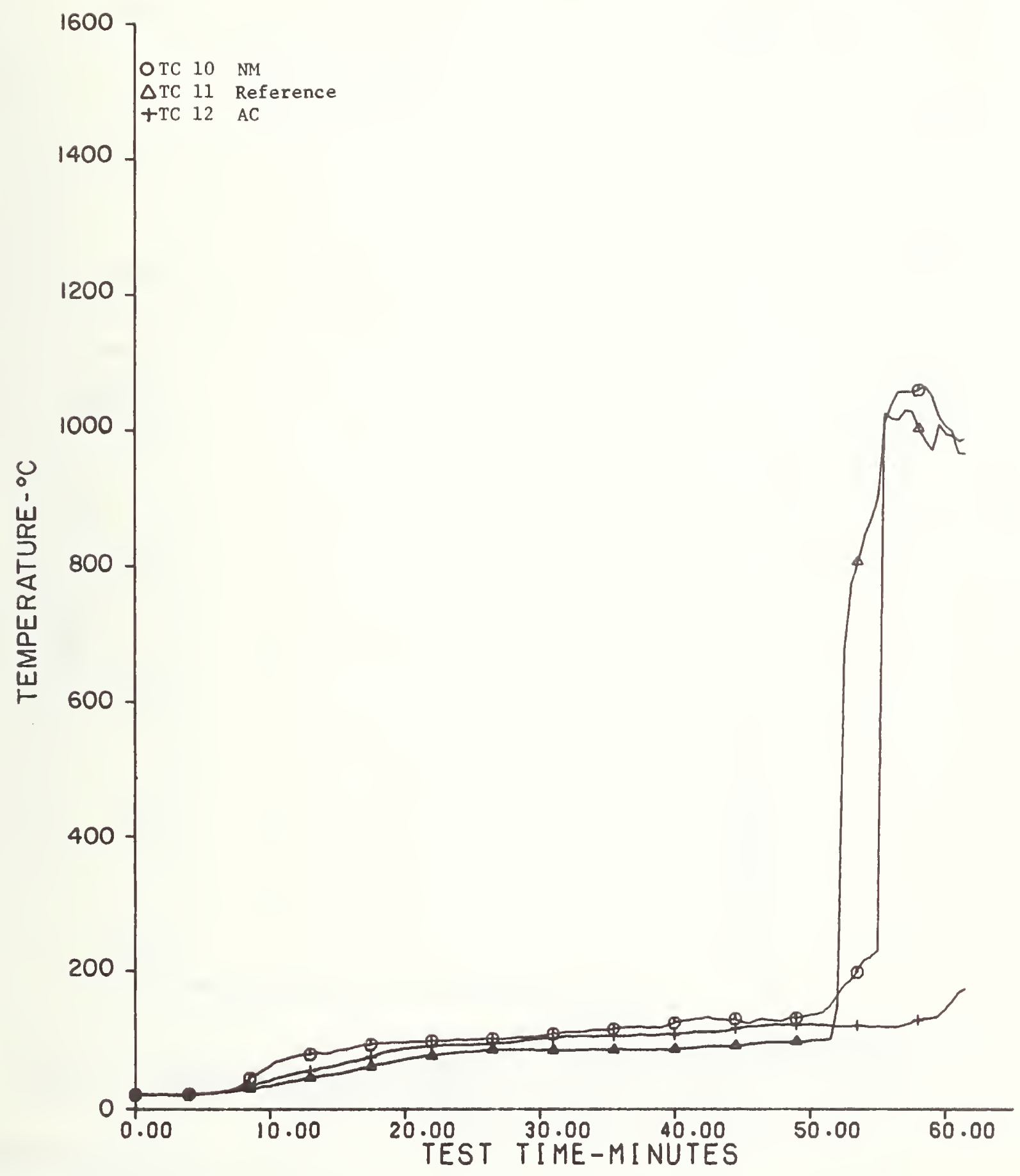

Figure 33. Test FE 2 - Alr temperatures floor space uninsulated wa11 


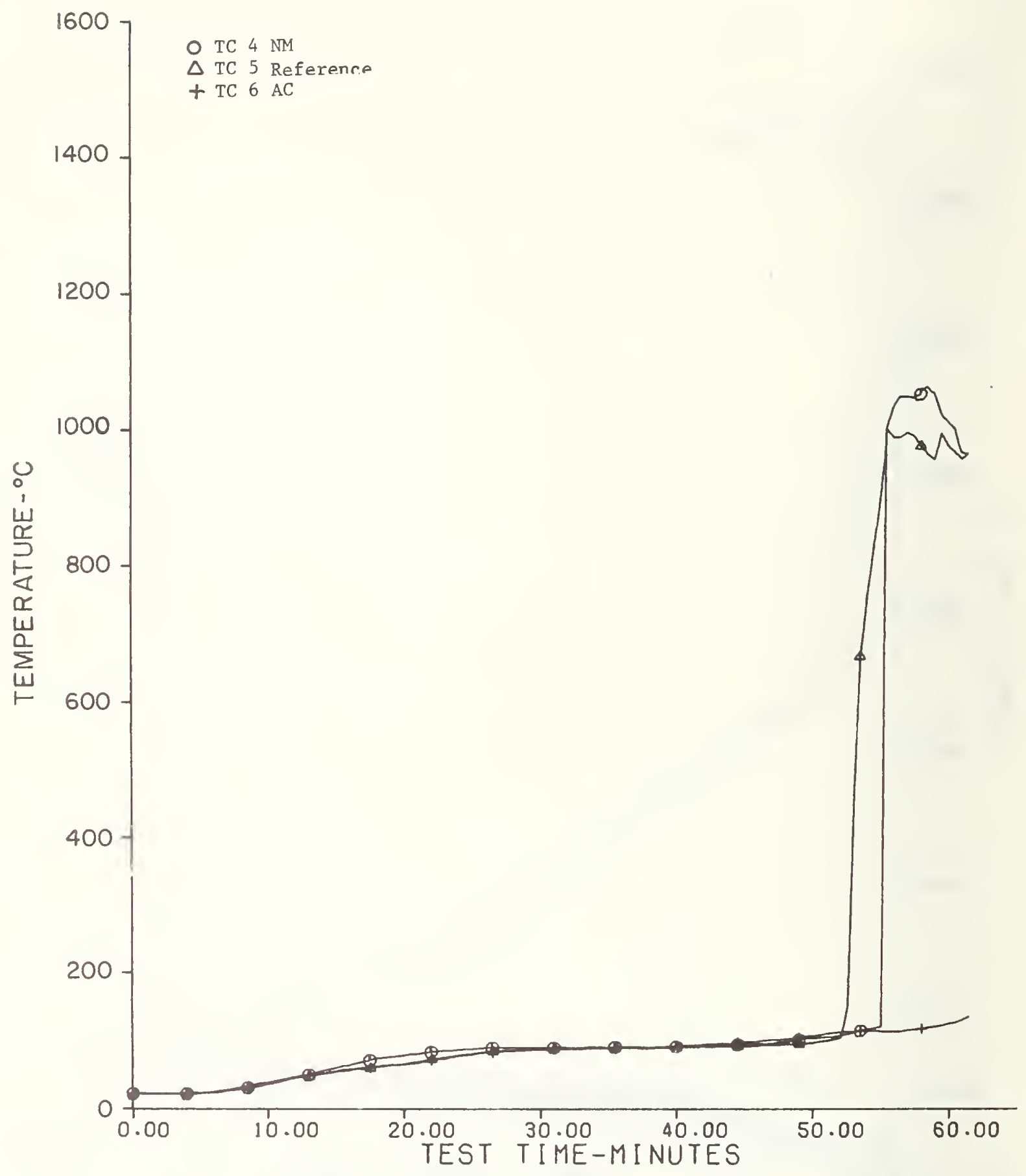

Figure 34. Test FE 2 - Air temperatures upper uninsulated wal1 


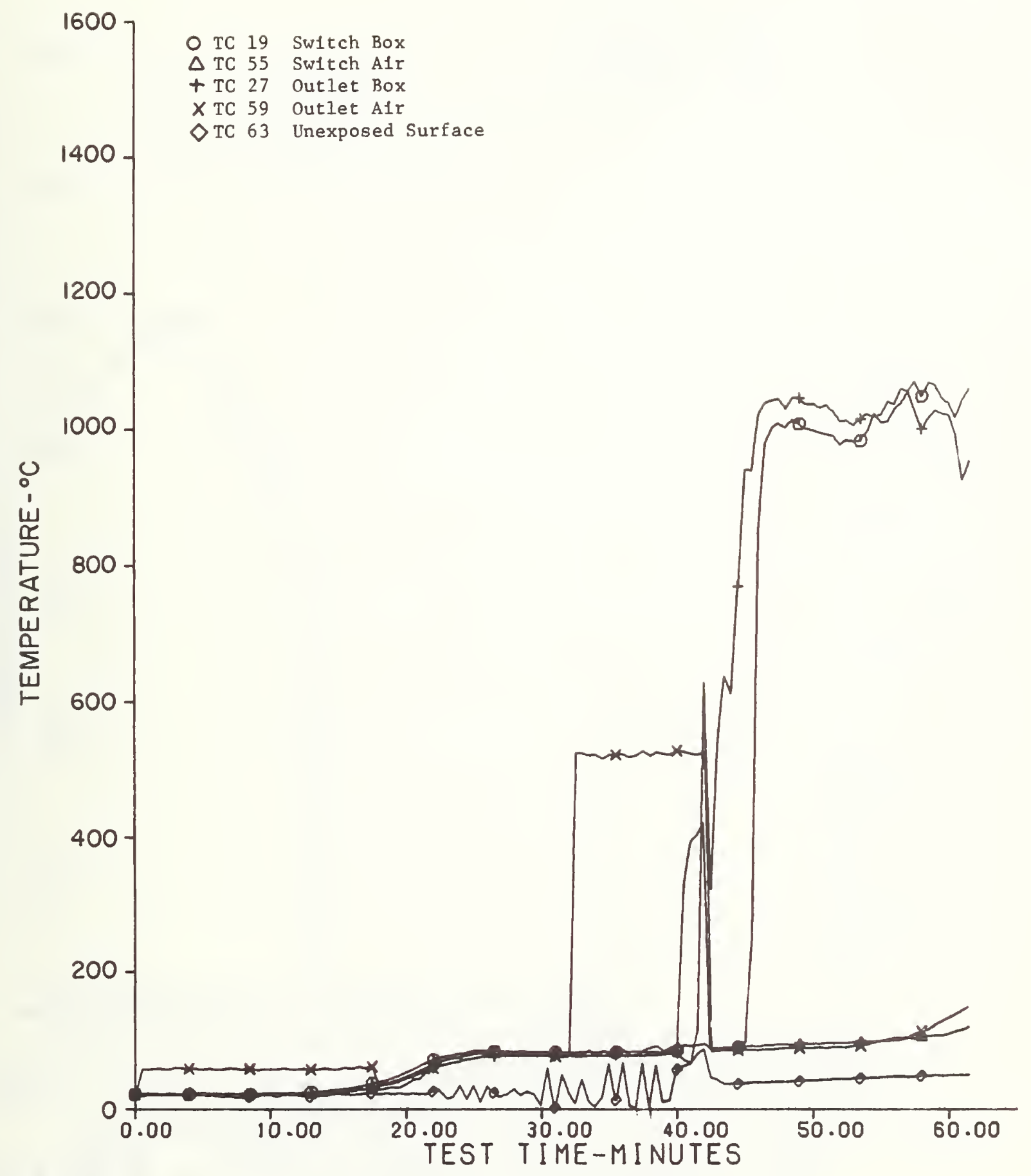

Figure 35. Test FE 2 - NM insulated upper wall room side \begin{tabular}{|lllll}
\hline 0 & TC & 10 \\
+ & TC & 27 \\
0 & TC & TC & 55 \\
0 & TC & 63
\end{tabular} temperatures 


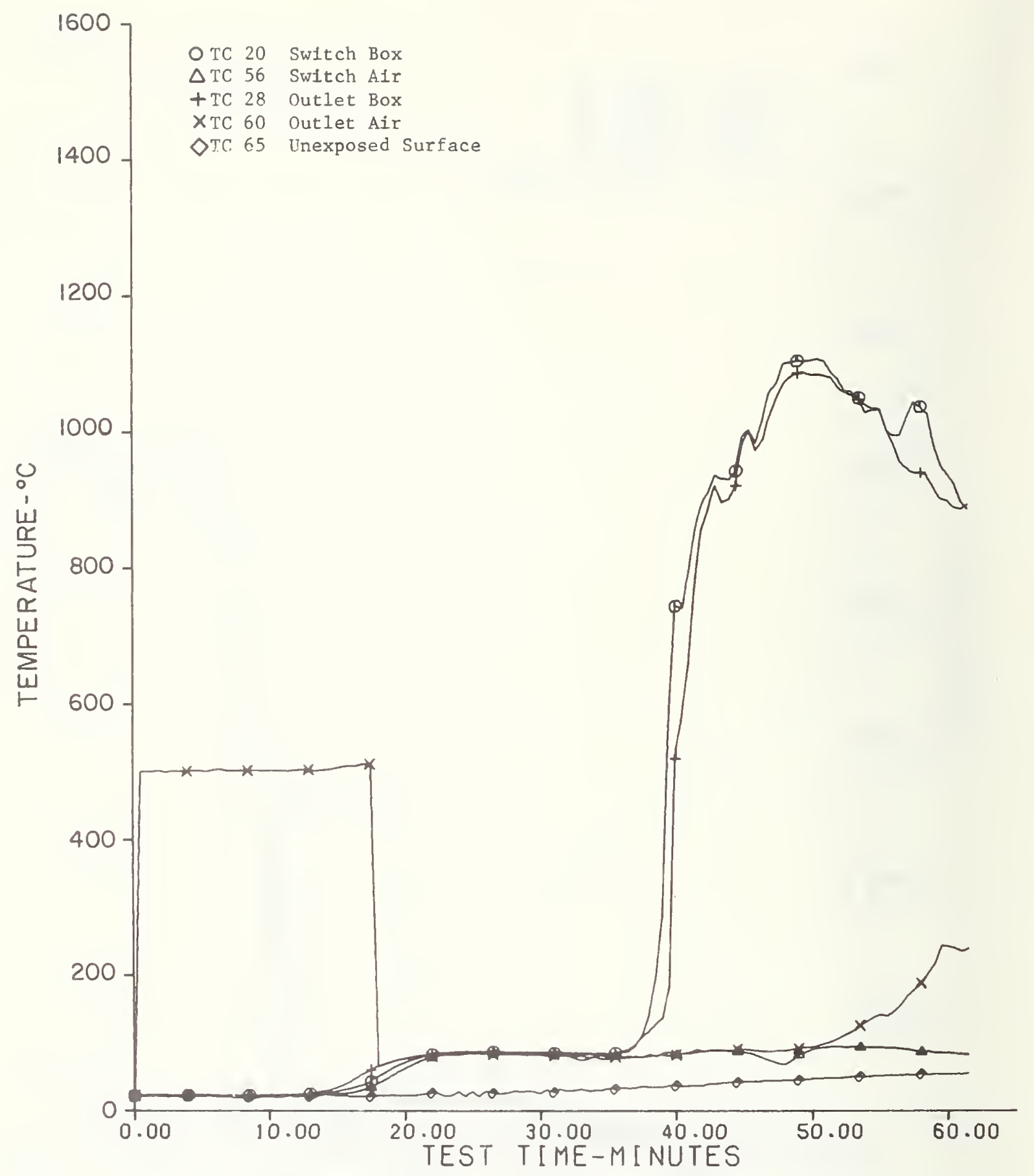

Figure 36. Test FE 2 - AC insulated upper wall room side temperatures 


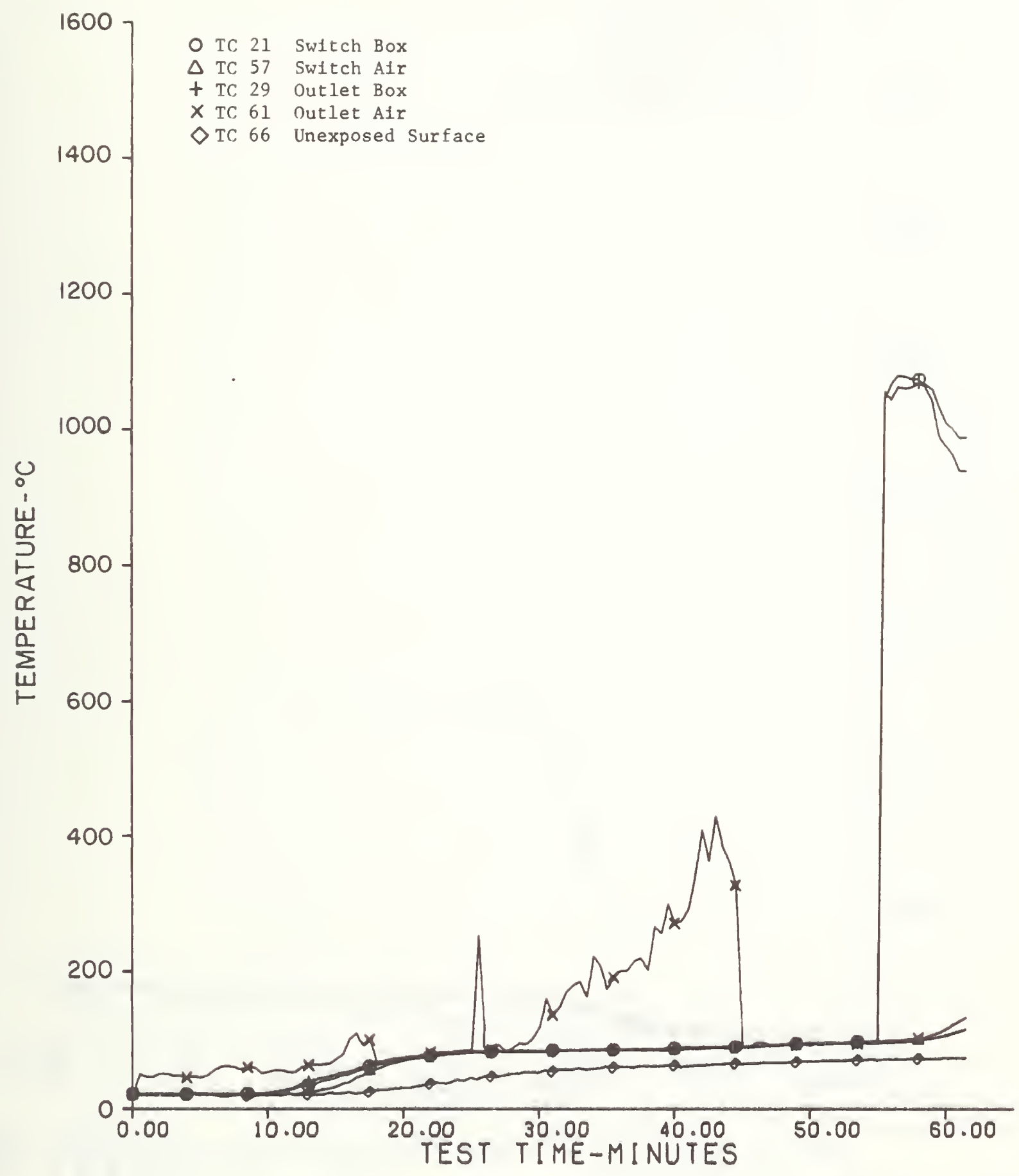

Figure 37. Test FE 2 - NM uninsulated upper wall room side temperatures 


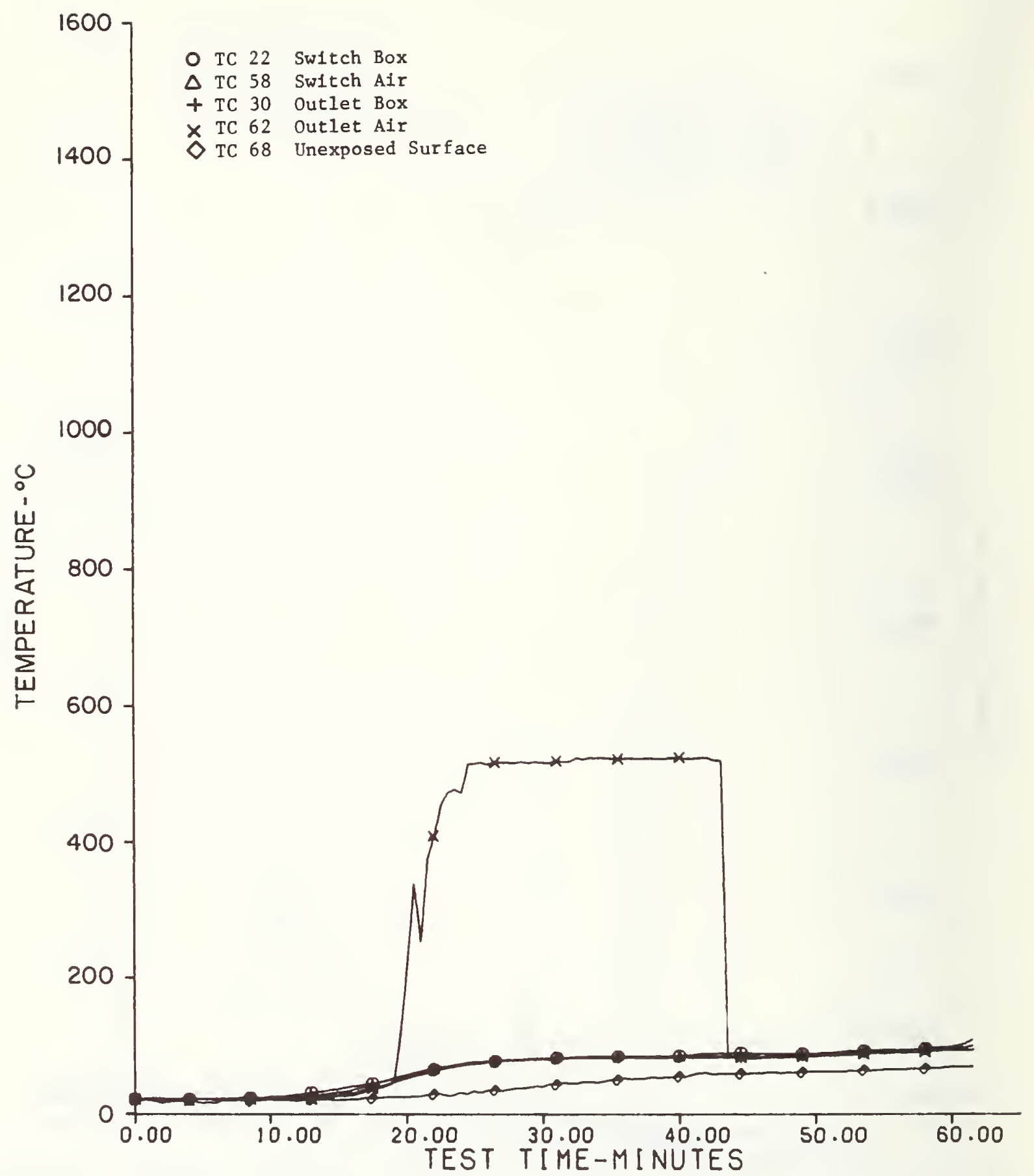

Figure 38. Test FE 2 - AC uninsulated upper wall room side temperatures 


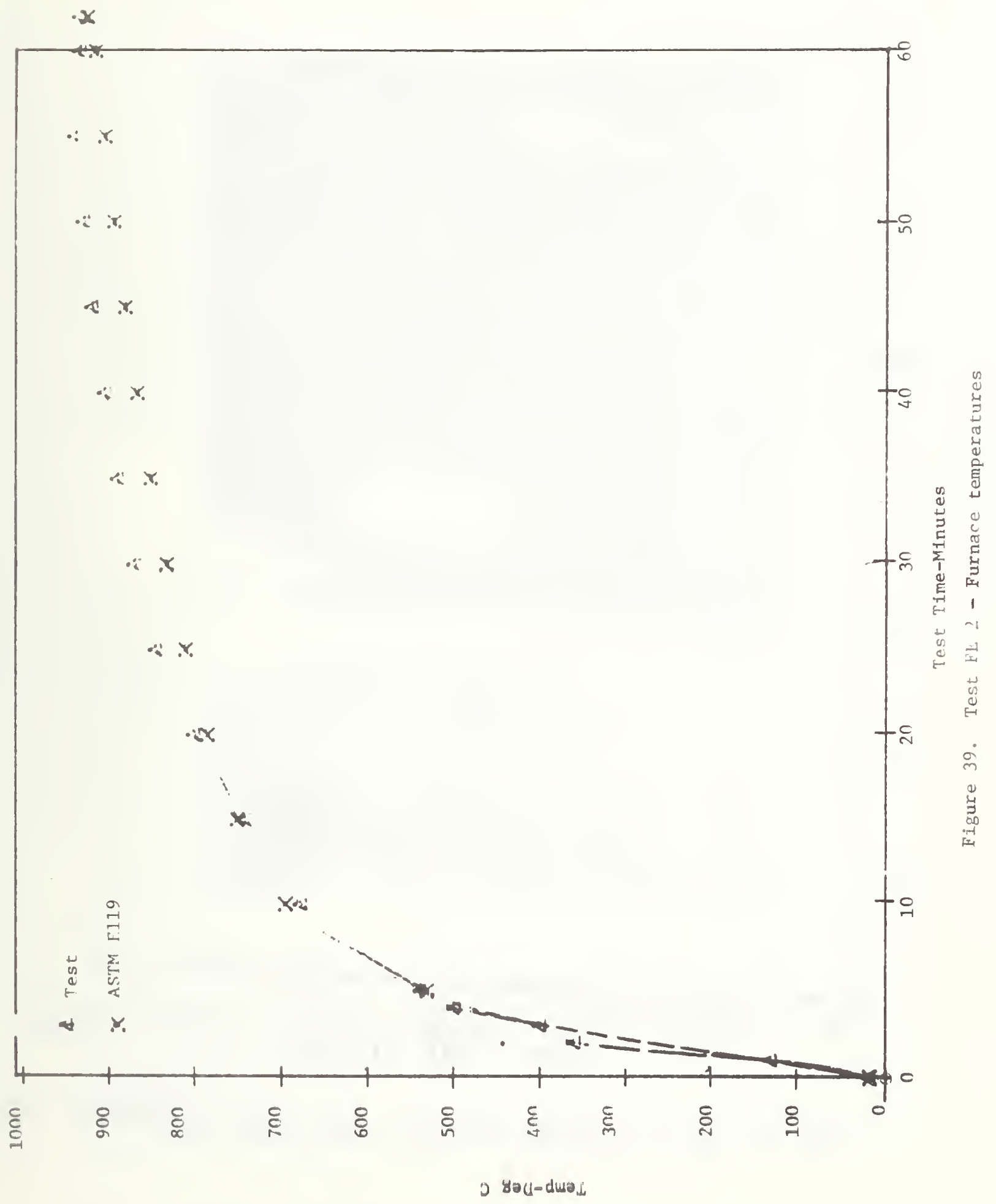




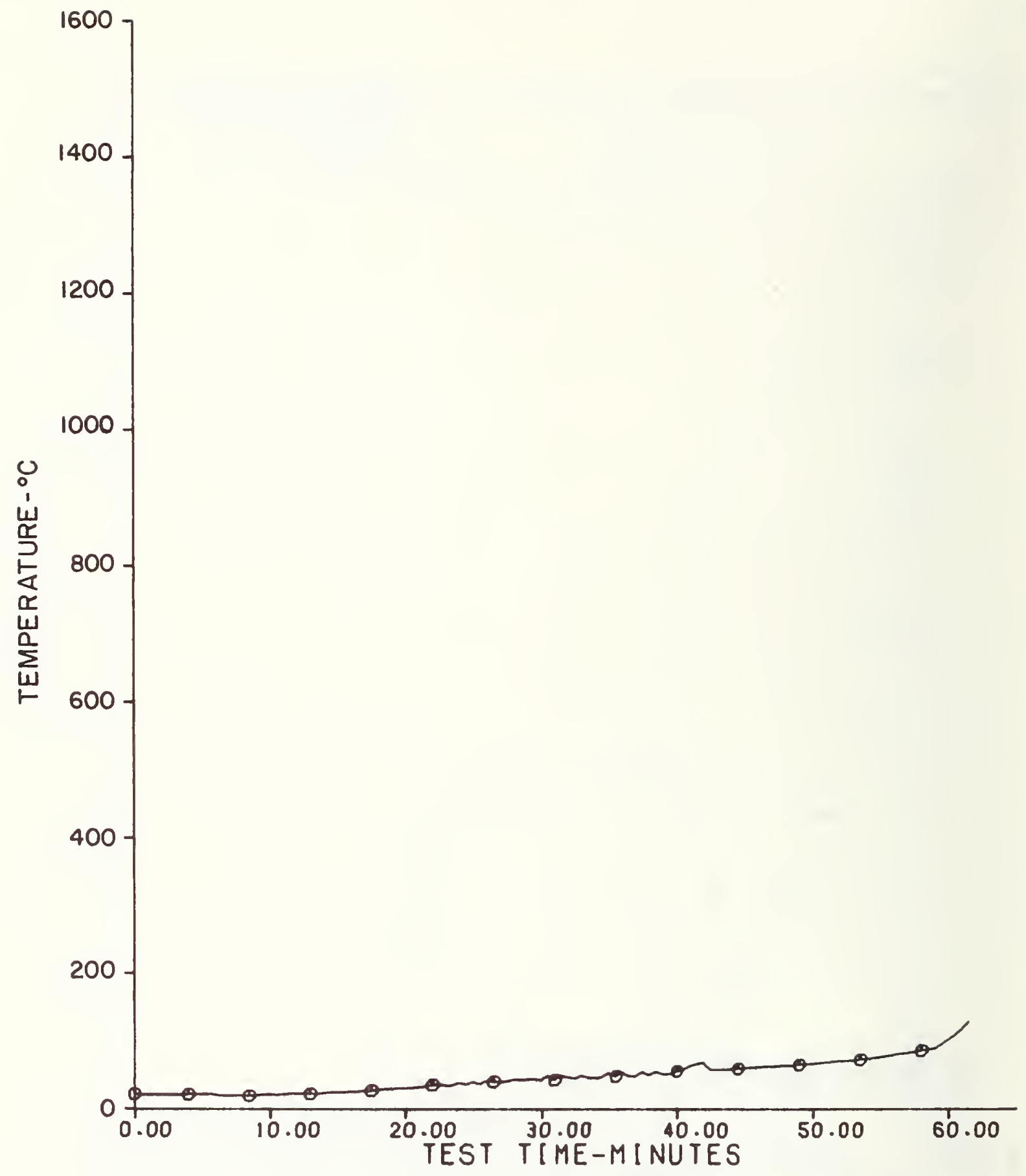

O TCAVO

Figure 40. Test FE 2 - Average unexposed surface temperatures 


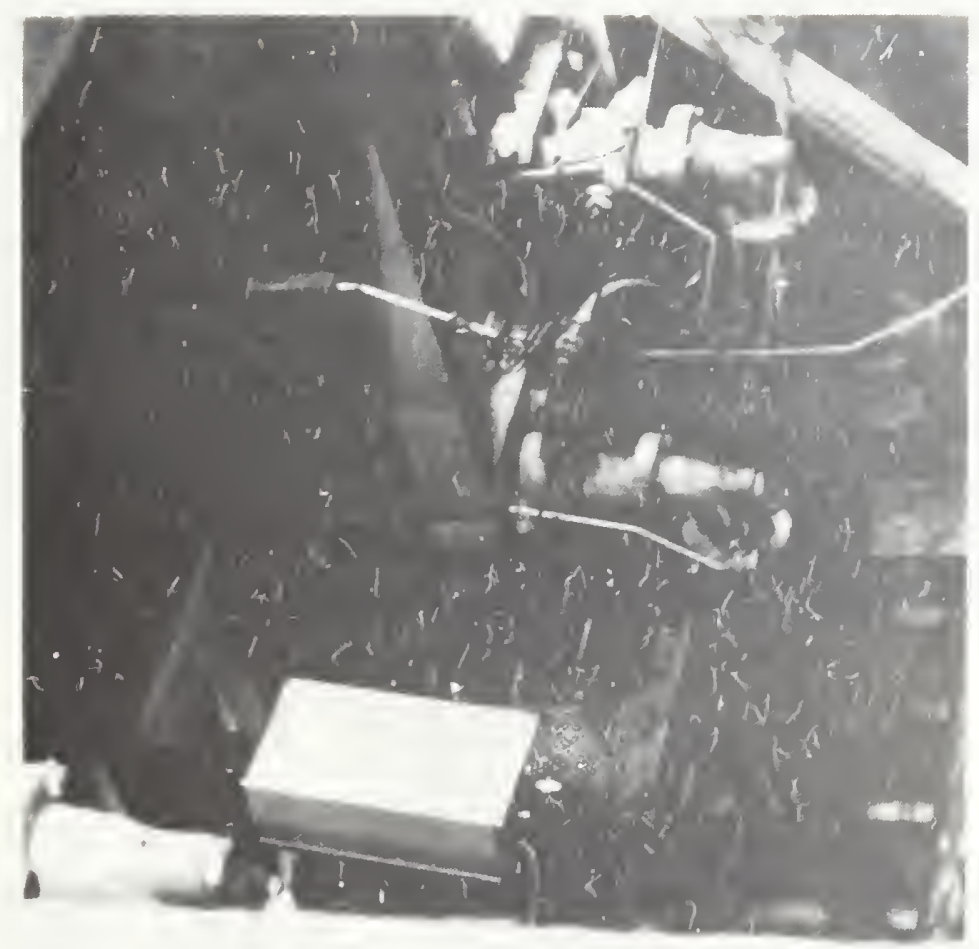

Figure 41. Test FE 2 - Mounted TV camera 


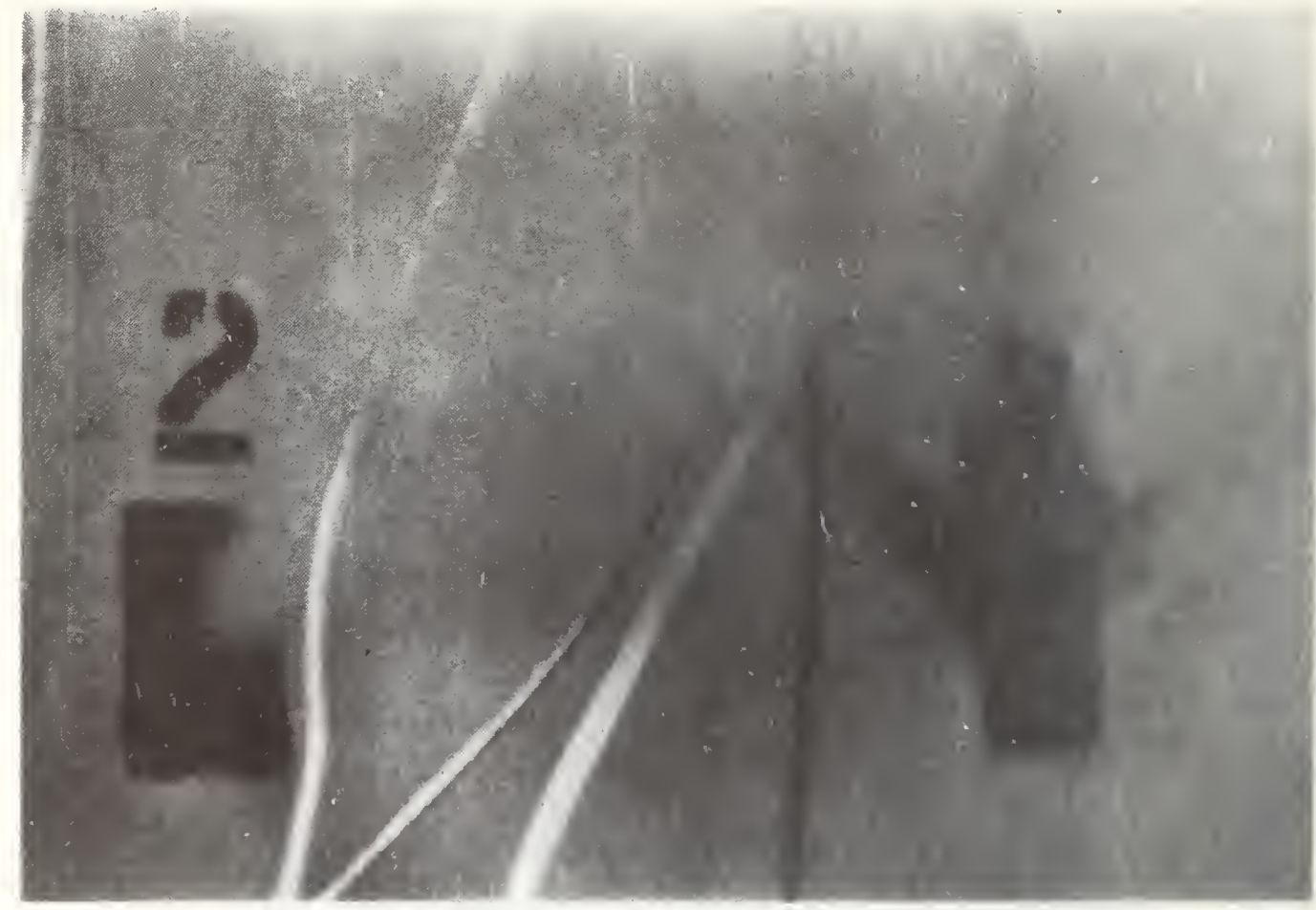

Figure 42. Test FE 1 - Smoke coming out of AC (2) insulated and NM uninsulated (3) switches

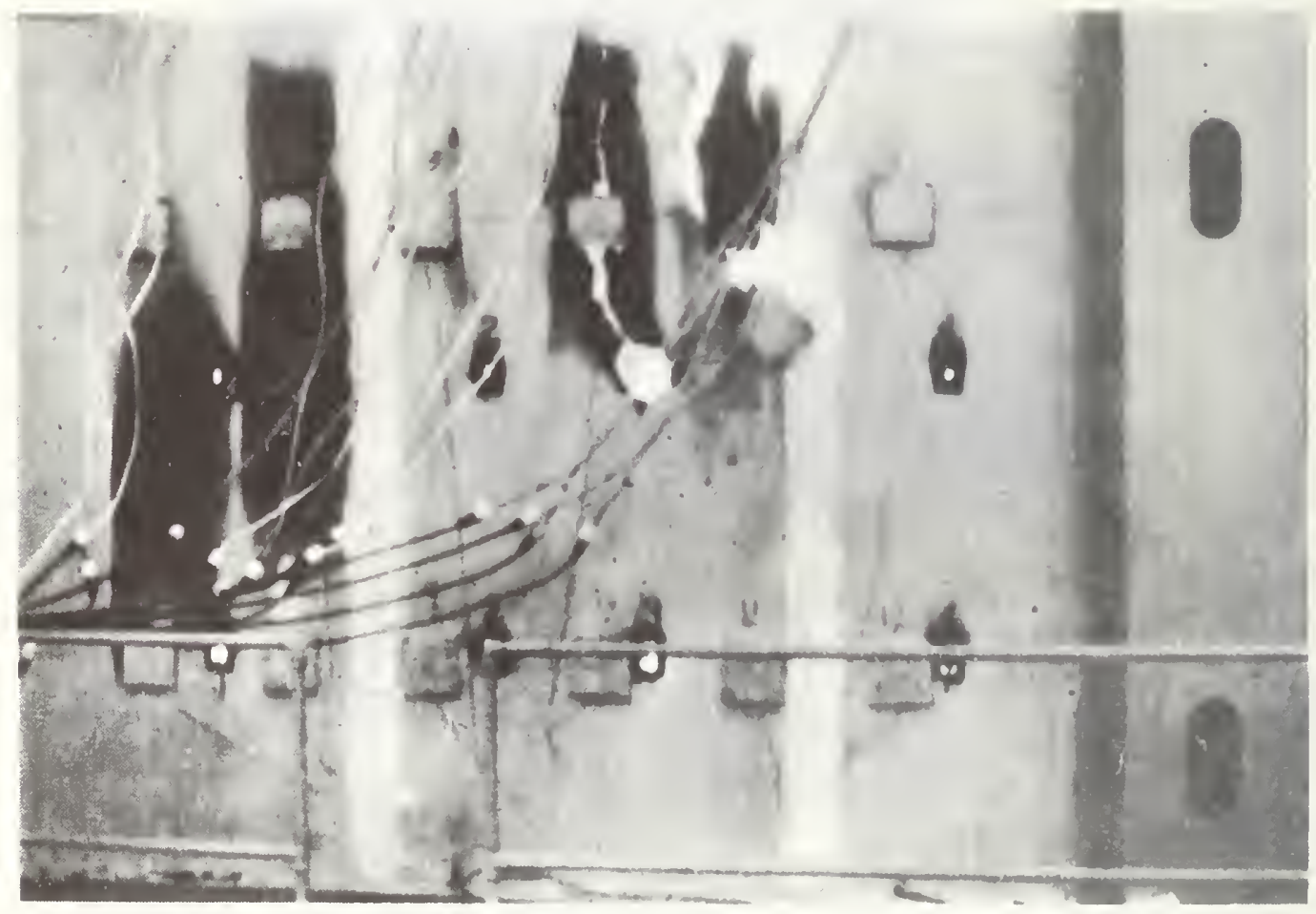

Figure 43. Test FE 1 - Front of furnace at end of test 


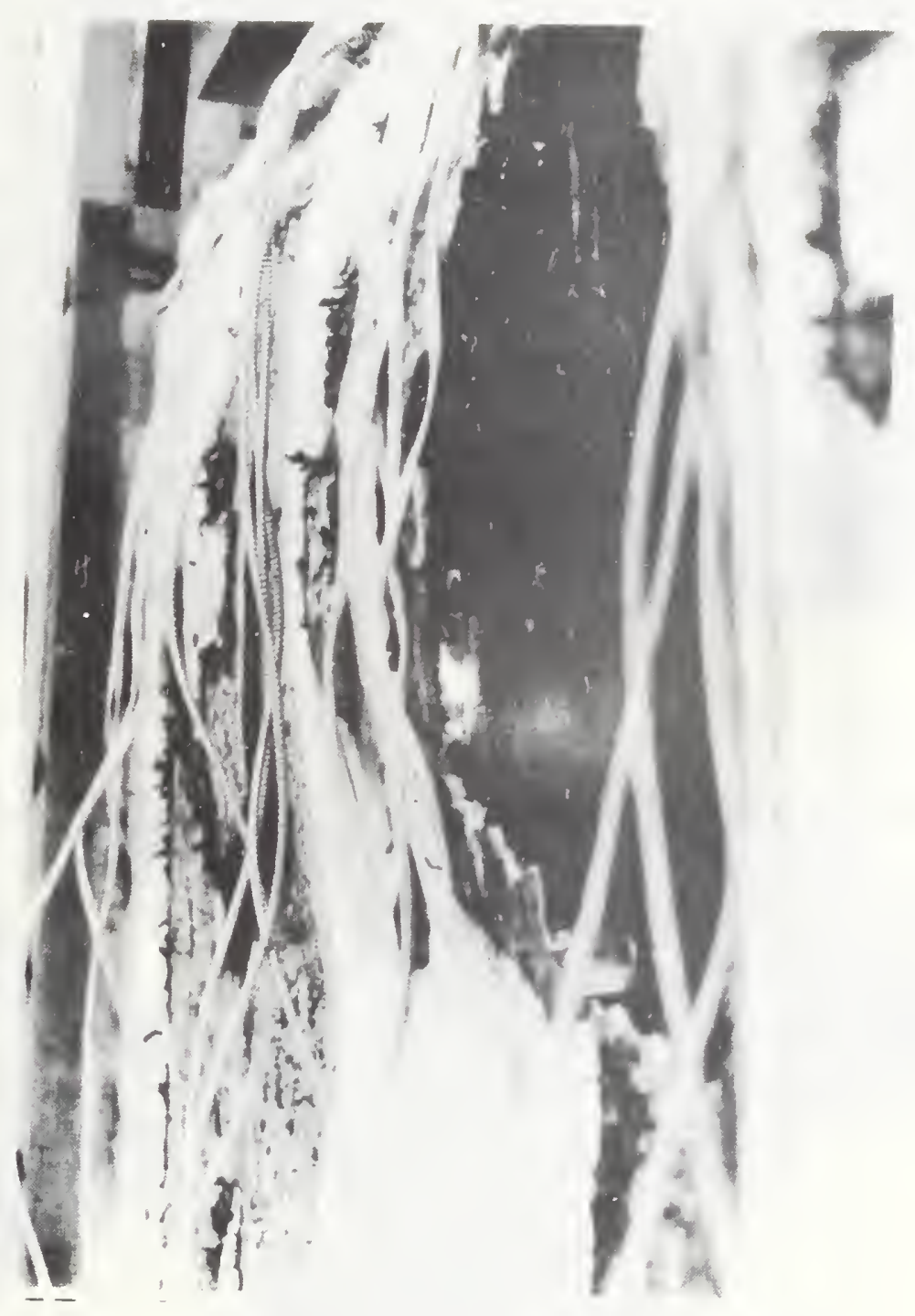

Figure 44. Test FE 1 - Front of furnace 3 hours after end of test 


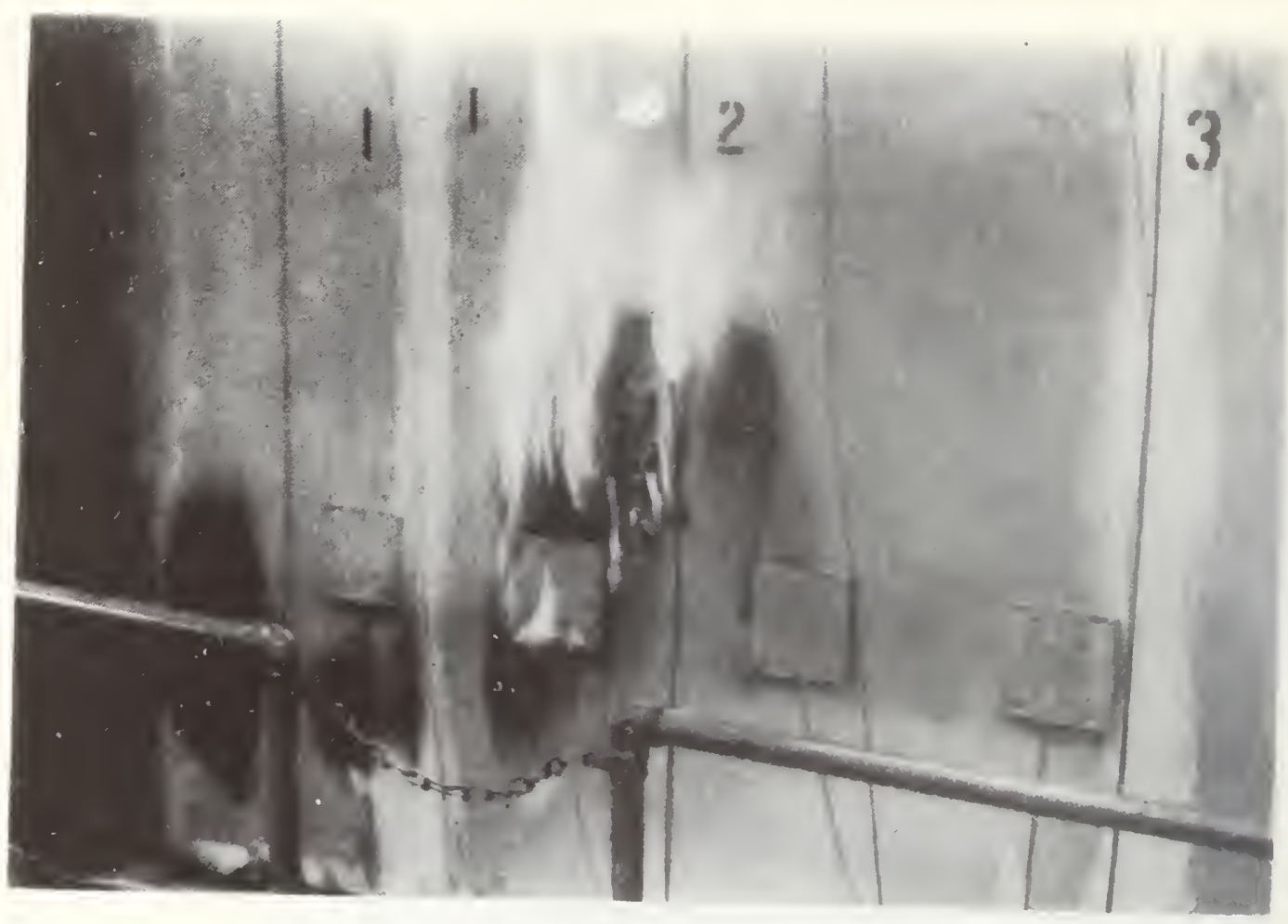

Figure 45. Test FE 2 - Burn-through at end of test

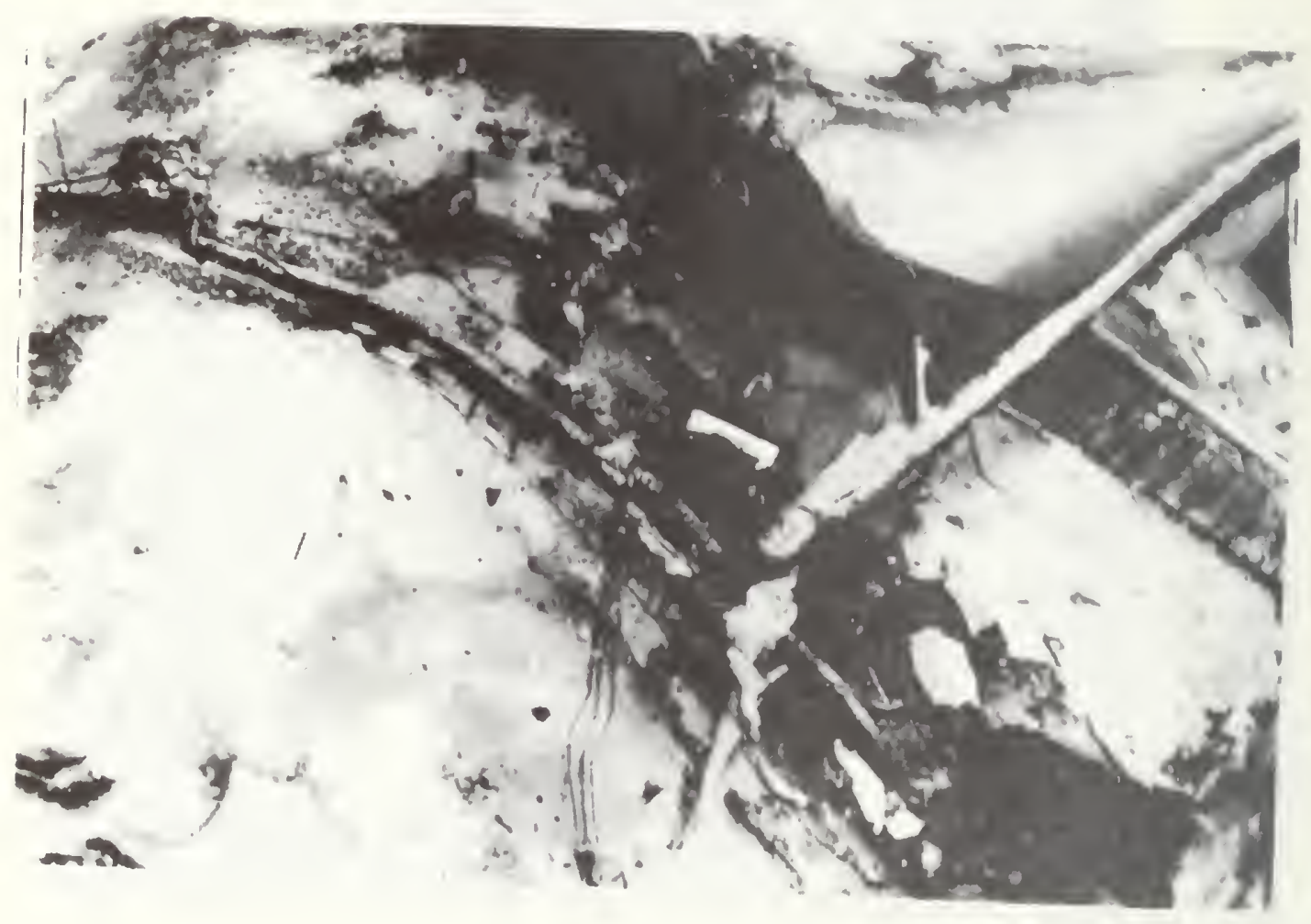

Figure 46. Test FE 2 - Condition of wall 2 hours after end of test 


\begin{tabular}{|c|c|c|c|}
\hline $\begin{array}{l}\text { U.S. OEPT. OF COMM. } \\
\text { BIBLIOGRAPHIC DATA } \\
\text { SHEET }\end{array}$ & $\begin{array}{l}\text { 1. PUIBLIC.ATION (OR RIEPORT NO. } \\
\text { NBSIR 78-1415 }\end{array}$ & $\begin{array}{l}\text { 2. Gov't Accession } \\
\text { No. }\end{array}$ & 3. Recipient's Accession No. \\
\hline \multirow{2}{*}{\multicolumn{3}{|c|}{$\begin{array}{l}\text { 4. Till AND SUBTITIE } \\
\text { Fire Endurance Tests of Residential Walls Containing } \\
\text { Branch Circuit Wiring - Preliminary Findings }\end{array}$}} & $\begin{array}{l}\text { 5. Publication Date } \\
\text { February } 1978\end{array}$ \\
\hline & & & 6. Performing Organization Cude \\
\hline \multicolumn{3}{|l|}{$\begin{array}{l}\text { 7. A IHA) } \\
\text { Lionel A. Issen }\end{array}$} & 8. Performing Organ. Report No. \\
\hline \multirow{2}{*}{\multicolumn{3}{|c|}{$\begin{array}{l}\text { 9. PERFORMING ORGANIZATION NAME AND ADDRESS } \\
\text { NATIONAL BUREAU OF STANDARDS } \\
\text { DEPARTMENT OF COMMERCE } \\
\text { WASHINGTON, D.C. } 20234\end{array}$}} & $\begin{array}{l}\text { 10. Project/Task/Work Unit No. } \\
4926385\end{array}$ \\
\hline & & & 11. Contract/Grant No. \\
\hline \multirow{3}{*}{\multicolumn{3}{|c|}{$\begin{array}{l}\text { 12. Sponsoring Organization Name and Complete Address (Street, City, State, ZIP) } \\
\text { Office of Policy Development and Research } \\
\text { U.S. Department of Housing and Urban Development } \\
\text { Washington, D.C. } 20410\end{array}$}} & $\begin{array}{l}\text { 13. Type of Report \& Period } \\
\text { Covered }\end{array}$ \\
\hline & & & Final Report \\
\hline & & & 14. Sponsoring Agency Code \\
\hline
\end{tabular}

15. SUPPLEMENTARY NOTES

16. ABSTRACT (A 200-word or less factual summary of most significant information. If document includes a significant bibliography or literature survey, mention it here.)

Two fire endurance tests were performed to study the effects of branch clrcuit electric wiring and wiring devices on the fire resistance of a gypsum board and wood stud one-hour fire-rated wall. The tests simulated potential fire spread between (a) horizontally adjacent occupancies and (b) vertically adjacent occupancies. Each test wall assembly included both nonmetallic sheathed cable (type NM) and armoured cable (type AC), with and without 3-1/2 inch thick glass fiber insulation. The tests were conducted with a slightly positive pressure in the furnace, to represent the overpressure generated in room fires.

The tests showed that the presence and penetrations of electric branch circuit cables and wiring devices lowered the fire resistance of a one-hour rated gypsum board and wood-stud wall by 13 minutes when based on flame penetration of the unexposed surface wallboard and by 23 minutes when based on flame penetration at the wiring devices. The tests showed no significant difference in the performance of the different cable types.

17. KEY WORDS (six to twelve entries; alphabetical order; capitalize only the first letter of the first key word unless a proper name; separated by semicolons)

Fire endurance; fire tests; PVC; smoke; walls; wiring;

branch circuits; electrical codes.

\section{[x Unlimited}

For Official Distribution. Do Not Release to NTIS

Order From Sup. of Doc., U.S. Government Prineing Office Washington, D.C. 20402, SD Cal. No. C13

Order From National Technical Information Service (NTIS) Springfield, Virginia 22151

\begin{tabular}{|l|c|}
$\begin{array}{l}\text { 19. SECURITY CLASS } \\
\text { (THIS REPURT) }\end{array}$ & 21. NO. OF PAGES \\
UNCLASSIFIED & 65 \\
\hline $\begin{array}{l}\text { 20. SECURITY CLASS } \\
\text { (THIS PAGE) } \\
\text { UNCLASSIFIED }\end{array}$ & 22. Price \\
$\$ 5.25$ \\
\hline
\end{tabular}


